\title{
The Kynurenine Pathway in Acute Kidney Injury and Chronic Kidney Disease
}

\author{
Hai Ning Wee ${ }^{a}$ Jian-Jun Liu ${ }^{b}$ Jianhong Ching ${ }^{a, c}$ Jean-Paul Kovalik ${ }^{a}$ \\ Su Chi Limb, d, e \\ aDuke-NUS Medical School, Singapore, Singapore; ${ }^{b}$ Clinical Research Unit, Khoo Teck Puat Hospital, \\ Singapore, Singapore; ‘KK Research Centre, KK Women's and Children's Hospital, Singapore, Singapore; \\ dSaw Swee Hock School of Public Health, National University of Singapore, Singapore, Singapore; \\ eDiabetes Centre, Admiralty Medical Centre, Singapore, Singapore
}

\section{Keywords}

Kynurenine · Tryptophan · Acute kidney injury · Chronic kidney disease $\cdot$ Uremia $\cdot$ Inflammation

\begin{abstract}
Background: The kynurenine pathway (KP) is the major catabolic pathway for tryptophan degradation. The KP plays an important role as the sole de novo nicotinamide adenine dinucleotide $\left(\mathrm{NAD}^{+}\right)$biosynthetic pathway in normal human physiology and functions as a counter-regulatory mechanism to mitigate immune responses during inflammation. Although the KP has been implicated in a variety of disorders including Huntington's disease, seizures, cardiovascular disease, and osteoporosis, its role in renal diseases is seldom discussed. Summary: This review summarizes the roles of the KP and its metabolites in acute kidney injury (AKI) and chronic kidney disease (CKD) based on current literature evidence. Metabolomics studies demonstrated that the KP metabolites were significantly altered in patients and animal models with AKI or CKD. The diagnostic and prognostic values of the KP metabolites in AKI and CKD were highlighted in cross-sectional and longitudinal human observational studies. The biological impact of the KP on the pathophysiol-
\end{abstract}

ogy of AKI and CKD has been studied in experimental models of different etiologies. In particular, the activation of the KP was found to confer protection in animal models of glomerulonephritis, and its immunomodulatory mechanism may involve the regulation of T cell subsets such as Th17 and regulatory T cells. Manipulation of the KP to increase NAD ${ }^{+}$production or diversion toward specific KP metabolites was also found to be beneficial in animal models of AKI. Key Messages: KP metabolites are reported to be dysregulated in human observational and animal experimental studies of AKI and CKD. In AKI, the magnitude and direction of changes in the KP depend on the etiology of the damage. In CKD, KP metabolites are altered with the onset and progression of CKD all the way to advanced stages of the disease, including uremia and its related vascular complications. The activation of the KP and diversion to specific sub-branches are currently being explored as therapeutic strategies in these diseases, especially with regards to the immunomodulatory effects of certain KP metabolites. Further elucidation of the KP may hold promise for the development of biomarkers and targeted therapies for these kidney diseases.

\section{(c) 2021 The Author(s).}

Published by S. Karger AG, Basel
(C) 2021 The Author(s)

Published by S. Karger AG, Basel

This is an Open Access article licensed under the Creative Commons Attribution-NonCommercial-4.0 International License (CC BY-NC) (http://www.karger.com/Services/OpenAccessLicense), applicable to the online version of the article only. Usage and distribution for commercial purposes requires written permission.
Correspondence to:

Jianhong Ching, jianhong.ching@ duke-nus.edu.sg 


\section{Introduction}

Kidney diseases represent a global health issue. Acute kidney injury (AKI) affects up to 1 in 5 hospitalized adult patients $[1,2]$ and is linked to a 4 -fold increase in in-hospital mortality [3]. Chronic kidney disease (CKD) accounted for 1.2 million deaths in 2017 and was the 12th leading cause of death worldwide [4]. Current renal biomarkers such as blood urea nitrogen and creatinine, though functional, are not as sensitive in detecting early disease and do not provide any information on the underlying etiologies of renal damage. The kynurenine pathway (KP) is the primary route for tryptophan (TRP) catabolism, accounting for around 95\% of dietary TRP degradation [5]. Physiologically, kynurenine (KYN) metabolites are crucial for energy metabolism and immune modulation. Pathologically, the KP has been implicated in a variety of disorders including Huntington's disease [6], seizures [7], cardiovascular disease [8], and osteoporosis [9]. However, its involvement in renal disease is seldom discussed. Here, we provide a balanced view of the KP and its metabolites in the pathophysiology of AKI and CKD, potential use as biomarkers, and possible relevance as interventional targets.

\section{Overview of the KP}

\section{KP and Its Metabolites}

TRP flux into the KP is controlled primarily by the first enzyme(s), namely tryptophan 2,3-dioxygenase (TDO) in the liver and indoleamine 2,3-dioxygenase (IDO) elsewhere in the body [10]. The KP can be further subdivided into 3 branches, as shown in Figure 1.

Nicotinamide adenine dinucleotide $\left(\mathrm{NAD}^{+}\right)$branch: $\mathrm{KYN}$ is converted to 3-hydroxykynurenine (3-HK), 3-hydroxyanthranilic acid (3-HAA), quinolinic acid (QUIN), and finally to $\mathrm{NAD}^{+}$, which is the preferred end product of the KP [11].

Picolinic acid (PA) branch: In the kidney and liver, KYN may be diverted to a second pathway to produce PA instead. One of the side products is glutaryl CoA, which is metabolized in the Krebs cycle to $\mathrm{CO}_{2}$ and ATP for energy. Amino- $\beta$-carboxymuconate-semialdehydedecarboxylase (ACMSD) is the enzyme for this branch [12] and is responsible for tipping KP metabolism away from NAD+ synthesis toward PA production.

Kynurenic acid (KYNA) branch: The third branch of the pathway, leading to the production of KYNA and xanthurenic acid (XA), is mediated by kynurenine ami- notransferases. This is a minor pathway under physiological conditions likely because of the enzyme kinetics of this metabolic route [10].

\section{KP in Energy Metabolism and Inflammation}

The KP is believed to play crucial roles in energy metabolism and inflammation. The KP is the sole de novo $\mathrm{NAD}^{+}$biosynthetic pathway, by which humans can derive $\mathrm{NAD}^{+}$from dietary amino acids [13]. In normal physiology, the KP is primarily directed toward the production of $\mathrm{NAD}^{+}$(via the $\mathrm{NAD}^{+}$branch) or glutaryl $\mathrm{CoA}$ (via the PA branch) for energy metabolism, as shown in Figure 1.

Mounting evidence supports inflammation as a key driver of TRP influx into the KP and, reciprocally, KP metabolites as key modulators of the inflammatory response. During inflammation, pro-inflammatory cytokines, mainly tumor necrosis factor- $\alpha$ (TNF- $\alpha$ ) and interferon- $\gamma$ (IFN- $\gamma)$, increase the catabolism of TRP down the KP by inducing IDO expression $[14,15]$. This results in an increase in KP metabolites from all subbranches, including NAD+ and KYNA, as shown in Figure 1 . The increase of flux down the KP during inflammation is believed to serve 2 important purposes - to provide energy for immune responses and to provide a counterregulatory mechanism to keep inflammation in check. From an evolutionary perspective, activated immune cells require a large amount of energy to fight off pathogen invasion, and hence the KP is activated to produce adequate amounts of $\mathrm{NAD}+$ for cellular respiration [7]. $\mathrm{NAD}+$ is also used as co-substrates for sirtuins and polyADP ribosylation polymerases, which can protect the host against oxidative stress related to inflammation. Importantly, many of the KP metabolites possess immunoregulatory properties that can mitigate the inflammation response. For example, KYNA is found to reduce proinflammatory cytokines [16], while KYN, 3-HK, and HAA can induce the apoptosis of Th1 and natural killer cells [7]. The activation of the KP is found to be essential for immune tolerance in pregnancy and organ transplantation $[17,18]$, and the immunosuppressive role of $\mathrm{KP}$ metabolites has been extensively reviewed $[16,17,19,20]$.

\section{$\mathrm{KP}$ in AKI}

\section{Definition and Common Etiologies of AKI}

AKI is defined as an abrupt deterioration in kidney function (within 7 days), leading to the retention of urea and other nitrogenous waste in the blood [21]. It is a 
Fig. 1. KP in health and inflammation. ACMSD, $\alpha$-amino- $\beta$-carboxymuconate- $\varepsilon$ semialdehyde-decarboxylase; ANA, anthranilic acid; 3-HAA, 3-hydroxyanthranilic acid; 3-HK, 3-hydroxykynurenine; IDO, indoleamine 2,3-dioxygenase; IFN- $\gamma$, interferon-gamma; IL-6, interleukin-6; KAT, kynurenine aminotransferases I-III; KMO, kynurenine 3-monooxygenase; KYN, kynurenine; KYNA, kynurenic acid; $\mathrm{NAD}^{+}$, nicotinamide adenine dinucleotide; PA, picolinic acid; QUIN, quinolinic acid; TDO, tryptophan 2,3-dioxygenase; TNF- $\alpha$, tumor necrosis factor-alpha; TRP, tryptophan; XA, xanthurenic acid; KP, kynurenine pathway. (Created with BioRender.com.)

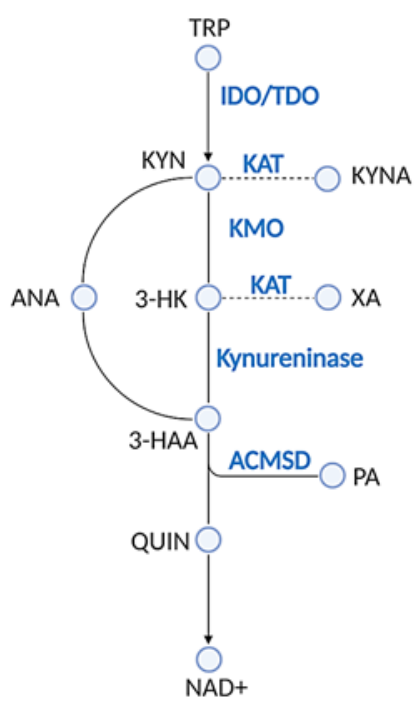

Health: the Kynurenine Pathway is essential for De novo biosynthesis of NAD+

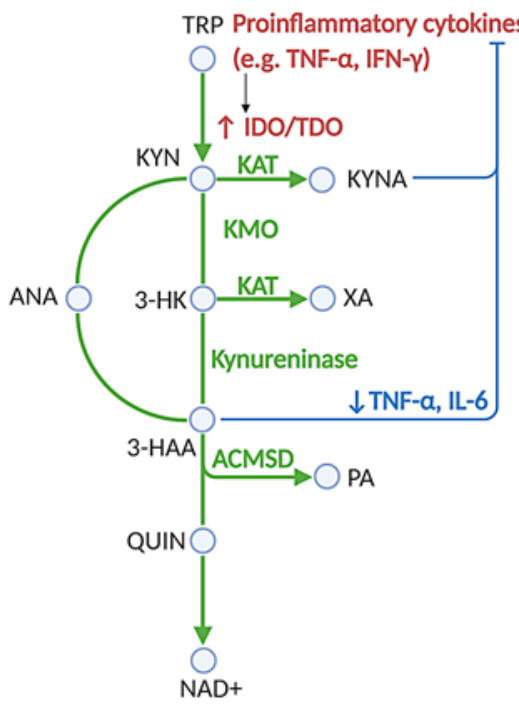

Inflammation: the Kynurenine Pathway also functions as a counter-regulatory mechanism to suppress inflammation broad clinical syndrome encompassing multiple etiologies, such as ischemia, sepsis, and drug-induced toxicity. The spectrum of injury ranges from mild to advanced [22], with an in-hospital mortality of up to $60 \%$ for severe cases requiring renal replacement therapy [23]. The longterm consequence for survivors includes progression to CKD, end-stage kidney disease (ESKD), and increased risk for cardiovascular diseases and mortality [24].

\section{KP Metabolites as Potential Biomarkers for AKI}

Most animal studies have shown that the KP is activated in AKI. TRP was reduced and KP metabolites such as KYN, KYNA, and 3-HK were elevated in the plasma [25] and kidney tissue [26] of mice with ischemia/reperfusion-induced AKI. Mice subjected to sepsis-associated AKI showed lower TRP and derangements in KYN, KYNA [27], and QUIN [28] compared to sham controls. Similarly, mice with AKI arising from drug-induced toxicity were found to have higher KYN $[29,30]$ and KYNA [29] in the blood. An exception is a study which found higher urinary TRP and lower urinary KYNA in newborn rats subjected to gentamycin-induced AKI [31]. One possible reason for this discrepancy is that gentamicin may specifically suppress IDO activity [32]. Mechanistically, the upregulation of KP metabolism during AKI may be explained by the increase in IFN- $\gamma$ and other pro-inflammatory cytokines. During AKI, the initial kidney damage

The Kynurenine Pathway in AKI and CKD and cell death evoke an acute inflammatory response involving resident and infiltrating leukocytes [33]. This inflammatory phase is mainly orchestrated and amplified by pro-inflammatory cytokines such as IFN- $\gamma$ and TNF- $\alpha$. Since both IFN- $\gamma$ and TNF- $\alpha$ are strong activators of IDO (the rate-limiting enzyme of the KP), the upregulation of the KP and increase of its metabolites during AKI may be attributed to these pro-inflammatory cytokines. While IDO is generally upregulated, some of the downstream $\mathrm{KP}$ enzymes such as kynurenase and quinolinate phosphoribosyltransferase were found to be downregulated in various models of AKI, resulting in further accumulation of the KP intermediates and an impairment of the de novo NAD+ biosynthesis via the $\mathrm{KP}[34,35]$.

In clinical observational studies, plasma and urinary KP metabolites were generally increased in patients with AKI of different etiologies, in agreement with animal data. Additionally, the increase in KP metabolites was correlated with inflammation and occurred early in the disease course. A cross-sectional study found that KYN/ TRP ratio (a proxy for IDO or TDO activity) was increased during AKI episodes in transplant patients [36]. A longitudinal study showed that KYNA was increased in septic shock patients with AKI, and the increase was correlated with the inflammatory marker procalcitonin [37]. It is noteworthy that treatment with dialysis reduced plasma KYNA only in survivors but not in non- 
Fig. 2. Manipulating KP as a therapeutic strategy in AKI. Experimental studies demonstrated that AKI may be alleviated by increasing KYNA production via inhibition of kynurenine 3-monooxygenase or increasing $\mathrm{NAD}^{+}$production via inhibition of ACMSD. ACMSD, $\alpha$-amino- $\beta$-carboxymuconate- $\varepsilon$ semialdehyde-decarboxylase; ANA, anthranilic acid; 3-HK, 3-hydroxykynurenine; $\mathrm{KMO}$, kynurenine 3-monooxygenase; KYN, kynurenine; KYNA, kynurenic acid; $\mathrm{NAD}^{+}$, nicotinamide adenine dinucleotide; $\mathrm{PA}$, picolinic acid; TRP, tryptophan; XA, xanthurenic acid; KP, kynurenine pathway; AKI, acute kidney injury. (Created with BioRender.com.)

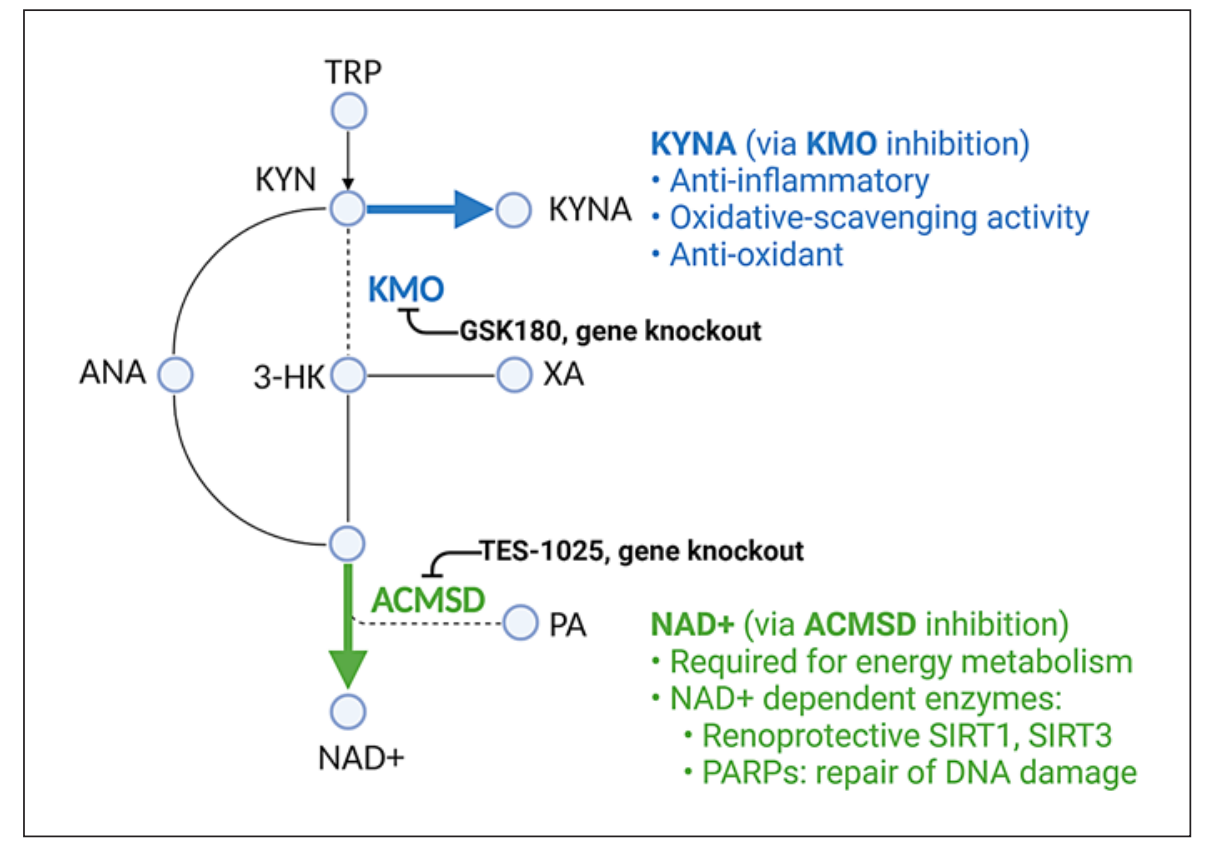

survivors, possibly due to persistent inflammation in non-survivors. Another longitudinal study monitored ICU patients with AKI of mixed etiologies. It reported a significant difference in urinary concentrations of TRP, KYN, KYNA, and 3-HAA between early recovering patients and those with late-/non-recovery [38]. In particular, KYNA increased early in the disease and was the single most important predictor of renal recovery on days 1 and 2. By comparison, creatinine levels were not significantly different between the 2 groups on day 1 and only became an important predictor of renal recovery by day 3. In the third longitudinal study, KYNA was part of a multimarker panel of 7 metabolites that predicted the risk of major adverse kidney events over a 28-day period in ICU patients with and without AKI [39]. In the fourth longitudinal study on hospitalized patients with cirrhosis, KYNA, QUIN, and PA were found to be higher in patients who developed AKI [40]. Additionally, KYNA was found to have prognostic value by predicting the progression to dialysis in patients who developed AKI. Current criteria for clinical diagnosis and staging of AKI (e.g., RIFLE, AKIN, KDIGO) are based on changes in serum creatinine and urine output [41]. However, the serum creatinine level is considered an insensitive biomarker for AKI because its rise is often delayed following kidney injury [41, 42]. Therefore, further studies are warranted to examine whether KP metabolites such as KYNA may serve as biomarkers for early detection of AKI.

\section{KP as Target for Prevention or Treatment of AKI}

The effect of IDO on AKI in preclinical studies appears to have differing results, depending on the models of AKI. In a model of ischemia/reperfusion-induced AKI, the inhibition of IDO, either pharmacologically using 1-methyltryptophan (1-MT) or genetically using IDO knockout mice, reduced the severity of AKI and ameliorated renal fibrosis $[43,44]$. This suggests that activation of IDO is deleterious and promotes ischemia/reperfusion (I/R) injury. By contrast, in a model of cisplatin-induced AKI [30], activation of the KP in renal dendritic cells via IDO led to an expansion of immunosuppressive regulatory $\mathrm{T}$ cells (Tregs) in the injured kidney and alleviation of AKI, suggesting that the function of the KP in AKI may be celland tissue-dependent.

Other studies investigated the consequences of manipulating KP enzymes downstream of IDO, as shown in Figure 2. Interestingly, the shunting of the KP toward the KYNA side branch consistently protected against AKI. Inhibition of the KMO enzyme, which results in diversion of the KP toward KYNA production, conferred significant protection against AKI arising from renal $I / R$ injury [25] and acute pancreatitis [45], as demonstrated by improvement in renal function and histological changes. Similarly, exogenous administration of KYNA protected against AKI induced by renal I/R injury [46, 47]. The protective effects of KYNA may be related to its anti-inflammatory, ROS-scavenging, and antioxidant activities [16]. 
The proapoptotic effects of QUIN, PA, and 3-HK may also partly explain why shunting of KP toward the KYNA side branch protected against various models of AKI [48, 49]. Unlike the aforementioned KP metabolites, KYNA does not seem to promote apoptosis in renal cells. Additionally, KYNA can inhibit TNF- $\alpha$ production and possesses antioxidant properties related to its ability to scavenge hydroxyl, superoxide anion, and other free radicals [16]. Hence, the diversion toward KYNA production via $\mathrm{KMO}$ inhibition may be explored as a potential therapeutic strategy for AKI.

Another interesting target for treatment of AKI is the ACMSD enzyme, which lies at the junction between the $\mathrm{NAD}+$ branch and the PA branch. Inhibition of the ACMSD enzyme, which increased the production of NAD+, protected against AKI in both I/R injury and cisplatininduced models, as demonstrated by improvement in renal function and histological scores [50]. The increased production of $\mathrm{NAD}^{+}$is believed to be beneficial by serving as cofactors for renoprotective sirtuins [51] and polyADP ribosylation polymerases, which are required for DNA repair [52].

\section{KP in CKD}

\section{Definition and Common Etiologies of CKD}

CKD is defined as an abnormality of the kidney structure or function for $\geq 3$ months [41], as diagnosed by abnormal GFR $\left(<60 \mathrm{~mL} / \mathrm{min} / 1.73 \mathrm{~m}^{2}\right)$ or persistent proteinuria. The most common types of CKD are diabetic kidney disease, hypertensive nephrosclerosis, and glomerulonephritis [41]. Regardless of etiology, a large proportion of patients with CKD may eventually progress to ESKD.

\section{Association of KP Metabolites with Onset and}

Progression of CKD

KP metabolites have been measured in CKD patients of mixed etiology in both cross-sectional and longitudinal studies. A cross-sectional study found that CKD patients had higher serum levels of IDO, KYN, and lower TRP compared to healthy controls and their KYN/TRP ratios correlated with disease stages [53]. Another cross-sectional study found that KYN/TRP could distinguish CKD patients from non-CKD patients and was independently associated with albuminuria-to-creatinine ratio after adjustment for CKD-related indices [54].

Three large-cohort longitudinal studies found KP metabolites to be increased during the onset of CKD. The first study monitored 1,434 participants with normal baseline eGFR in the Framingham Heart Study for 8 years [55]. It found that KYN and KYNA were associated with incident CKD, even after adjustment for eGFR, age, sex, diabetes, hypertension, and proteinuria at baseline. Inclusion of KYN and KYNA in a multimarker panel of 5 metabolites improved the discrimination and classification of incident CKD. The second study examined the longitudinal associations of metabolites with CKD incidence in 1,104 participants in Augsburg, Germany [56]. KYN/TRP was found to be associated with annual eGFR decline and incident CKD in 7 years' follow-up. The third study followed 1,741 subjects from Korea over 8 years and found that KYN and KYN/TRP were positively associated with new-onset CKD [57]. Inclusion of KYN and KYN/ TRP into a panel of 4 metabolites improved the prediction of new-onset CKD. Collectively, these 3 large-cohort studies demonstrated the potential predictive value of KP metabolites such as KYN and KYNA for incident CKD. It should be noted that KYNA (and possibly KYN) relies on tubular secretion in addition to glomerular filtration for clearance from the serum, which makes them potential markers of non-GFR-related renal function [55]. The potential of KYN to be used as a predictor of CKD across different ethnic populations has been highlighted in a meta-analysis [58]. Out of the 233 metabolites analysed, KYN had the best score as a CKD biomarker.

Two longitudinal studies have studied the association of KP metabolites with risk for CKD progression. The first longitudinal study found no significant differences in plasma TRP, KYN, or KYNA between 40 fast progressors and 40 slow progressors [59]. This study is limited by a small sample size and short follow-up period. The second longitudinal study monitored 3,075 CKD patients for CKD progression (defined as $50 \%$ decline in eGFR in a median follow-up of 6.0 years) [60]. Notably, the study measured both plasma and urinary concentrations to compute the kidney clearances of suspected secretory solutes as an estimate of tubular secretion function. The authors found that a lower kidney clearance of KYNA showed the strongest association with CKD progression out of the 11 metabolites monitored, suggesting that kidney clearance of KYNA may provide complementary information to existing measurements of GFR and albuminuria for the assessment of kidney health [60].

\section{KP in CKD Secondary to Specific Causes}

There were fewer clinical studies on cause-specific CKD and they were mostly cross-sectional studies with relatively small sample size. 


\section{Diabetic Kidney Disease}

Two cross-sectional studies showed that plasma KYN, KYNA, QUIN [61], and KYN/TRP [62] were increased in patients with diabetic kidney disease (DKD) and correlated with eGFR. Four other observational studies found that KYN levels were positively associated with proteinuria $[63,64]$ and could distinguish between DKD patients with macroalbuminuria and diabetic patients without albuminuria $[65,66]$. A small longitudinal study showed that urinary KYNA could differentiate between progressive albuminuria and non-progressive albuminuria in patients with type 1 diabetes [67]. Immunostaining of kidney sections from DKD animal models revealed higher levels of IDO in the diabetic kidney than in control [68], and the levels of IDO were positively correlated with M1 macrophage and monocytes [69].

\section{Hypertension-Related CKD}

KP metabolites have been considered as potential biomarkers for hypertension-related kidney disease. Etiologically, there is a clear distinction between hypertensive nephrosclerosis (kidney damage due to chronic hypertension) and renovascular hypertension (hypertension secondary to kidney diseases). Correlations with KP metabolites have been observed for both conditions. In an observational study, KYN was one of the top 5 metabolites which might discriminate patients with biopsy-proven hypertensive nephrosclerosis from healthy controls [70]. In a rat model of renovascular hypertension, increased levels of KYN, KYNA, 3-HK, and AA and reduced levels of TRP were observed, with KYN independently associated with mean blood pressure [71].

\section{Chronic Glomerulonephritis}

In an observational study, KYN was found to be higher in patients with renal failure due to chronic glomerulonephritis as compared to healthy controls [72]. A small pilot study on patients with IgA nephropathy found KYN to be associated with disease severity and ANA to correlate with proteinuria [73]. Interestingly, in a murine model for crescentic glomerulonephritis, KYN/TRP ratio was found to be increased in the serum and renal tissue. Immunohistochemistry revealed an upregulation of IDO in glomerulus and renal tubular epithelial cells of the mice [74]. The clinical implication of the finding remains to be elucidated.

\section{Inflammation as the Main Driver of KP Activation in CKD}

The defense and repair adaptations after onset of kidney injury can be broadly categorized into hemodynamic and nonhemodynamic changes $[41,75]$. In the presence of unresolved injury, several common pathways may converge to perpetuate and exacerbate $C K D$ regardless of the primary causes. The hemodynamic changes in CKD are primarily mediated by the renin-angiotensin-aldosterone system. The primary nonhemodynamic component is chronic inflammation, while renal fibrosis represents a failed wound-healing process of the kidney tissue following persistent injury and unresolved inflammation. CKDrelated factors that may induce and/or perpetuate chronic inflammation include advanced glycation end products, vasoactive agents (e.g., angiotensin II), reactive oxygen species, and uremic toxins [75]. These factors can activate nuclear factor kappa-light-chain-enhancer of activated $B$ cells $(N F-\kappa B)$, the master regulator of inflammation, and induce the release of pro-inflammatory cytokines TNF- $\alpha$ and IFN- $\gamma$, both of which are potent inducers of the KP rate-limiting enzyme IDO. In corollary, several observational studies found high correlations between KP metabolites and inflammation in CKD patients. In a cross-sectional study, KYN, KYNA, QUIN levels, and IDO activity (KYN/TRP ratio as proxy) were positively correlated with inflammatory markers (hsCRP and soluble TNF receptor-1) in CKD patients [76]. In another cross-sectional study, 3-HAA level was independently associated with increased monocyte chemoattractant protein- 1 and macrophage inflammatory protein- $1 \beta$ in CKD patients [77]. A cross-sectional study on ESKD patients found ANA to be significantly correlated with ferritin, a commonly used inflammatory marker in hemodialysis [78].

The Potential Protective Role of KP in CKD - Effects of KP Activation on Intrarenal Inflammation and

\section{Fibrosis}

In vivo preclinical studies consistently demonstrated a protective role for KP and its metabolites in glomerulonephritis [74, 79-81]. The protection conferred by KP activation seems to be related to its anti-inflammatory effects, especially its ability to induce phenotype switching of the T lymphocytes.

T lymphocytes are known to differentiate into distinct phenotypes with opposing functions during the inflammatory and repair phases, driven mainly by cytokines such as IFN- $\gamma$ and IL-4. In a mouse model of crescentic glomerulonephritis [74], the pharmacological inhibition of IDO by 1-MT aggravated the kidney disease, as shown by increased glomerular crescent formation, accumulation of $\mathrm{CD} 4+\mathrm{T}$ cells and macrophages in renal tissue. Moreover, 1-MT-treated mice had higher levels of IFN- $\gamma$ 


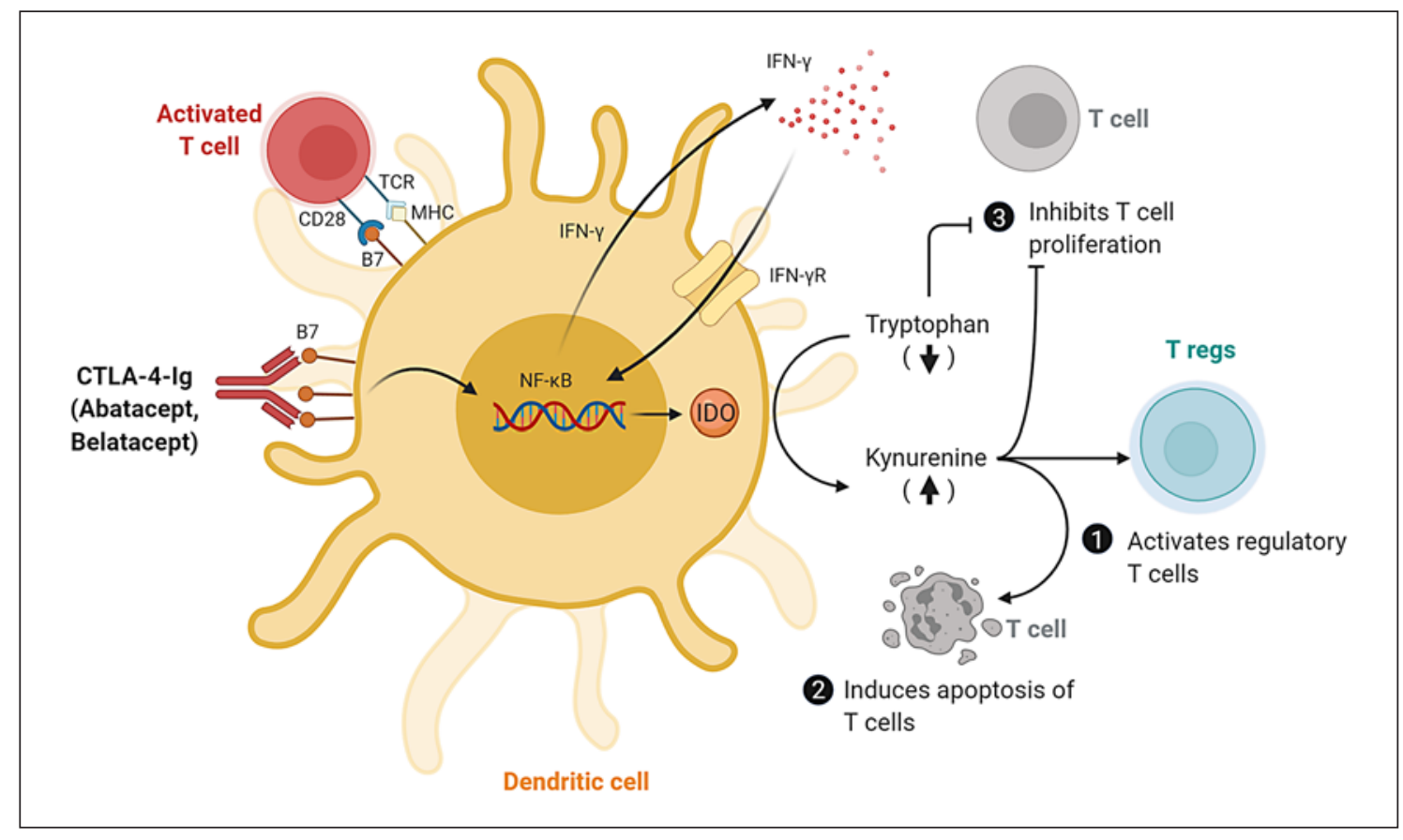

Fig. 3. KP activation by CTLA-4-Ig in dendritic cells and their effects on T lymphocytes. CTLA-4-Ig engages B7 receptor on dendritic cells to induce the production of IFN- $\gamma$ and promote the upregulation of IDO and activation of KP. This leads to an accumulation of the KP metabolites and a depletion of TRP, which can activate Tregs (1), induce apoptosis of T cells (2), and inhibit the proliferation of T cells (3). B7, B7 costimulatory molecule; CTLA-4-Ig, Cytotoxic T lymphocyte-associated antigen-4-immunoglobulin; IDO, indoleamine 2,3-dioxygenase; IFN- $\gamma$, interferon-gamma; IFN- $\gamma \mathrm{R}$, interferon-gamma receptor; $\mathrm{MHC}$, major histocompatibility complex; NF- $\kappa \mathrm{B}$, nuclear factor kappa-light-chain-enhancer of activated B cells; Tregs, regulatory T cells; TCR, T-cell receptor; KP, kynurenine pathway; TRP, tryptophan. (Adapted from Finger and Bluestone [200] and created with BioRender.com.)
(Th1 cytokine) and lower IL-4 (Th2 cytokine), suggesting that IDO is important in maintaining the Th1/Th2 balance during crescentic glomerulonephritis. In a mouse model of IgA nephropathy [80], the administration of the IDO inhibitor 1-MT worsened renal injury, increased Th17-related cytokine expression, and increased the Th17/Tregs ratio in kidney tissues. Conversely, the administration of either the IDO agonist ISS-ODN [80] or dendritic cells with overexpression of IDO [81] protected IgA nephropathy mice against renal injury, reduced Th17-related cytokines, and reduced the Th17/Tregs ratio in the kidney. These data suggest that IDO may confer protection against IgA nephropathy by regulating the Th17/Tregs immune balance. In a mouse model of antiglomerular basement membrane glomerulonephritis (anti-GBM GN), the knockout of IDO gene increased disease severity and mortality, whereas the induction of IDO gene protected the mice against antibody-mediated damage to the kidney and improved renal function [82]. In another study, treatment with 3-HK attenuated glomerular immune infiltrates, reduced pro-inflammatory cyto- kines, improved renal function, and increased survival in a mouse model of anti-GBM GN [83]. In a rat model of anti-GBM GN, treatment by either 3-HAA or 3-HK attenuated the kidney disease, improved renal function, reduced glomerular histological injury, and lowered renal infiltration of CD4+ T cells and macrophages [79]. This was associated with increased apoptosis and decreased proliferation of splenic CD4+ T cells in vivo. The splenic T cells from 3-HAA- or 3-HK-treated rats also exhibited increased Th2 cytokines (IL-4, IL-10) and decreased Th1 cytokines (IFN- $\gamma$, IL-12) ex vivo. These data suggest that KP metabolites such as 3-HAA or 3-HK may protect against anti-GBM GN by inducing an immune switch from Th1 to Th2 phenotype. Taken together, the experimental findings highlight the key immunosuppressive roles of the KP and its metabolites in various forms of glomerulonephritis.

Intrarenal fibrosis is an important pathway leading to progressive loss of kidney function. IDO [84] and KP metabolites such as KYN and KYNA $[85,86]$ were found to be increased during renal fibrosis in the CKD model 
induced by unilateral ureteral obstruction. Further experiments using tubular cell culture showed that IDO was increased after cells were exposed to TGF- $\beta 1$ [84]. In turn, the inhibition of IDO by 1-MT exacerbated TGF- $\beta 1$-induced epithelial-to-mesenchymal transition, which is believed to be part of the fibrotic "repair" mechanism that has gone awry due to sustained renal injury and non-resolving inflammation [87]. The findings showed that increased IDO during renal fibrogenesis may be a compensatory response that has a renoprotective effect by reducing epithelial-to-mesenchymal transition.

\section{Mechanisms of Immunosuppression Arising from KP} Activation and Potential for Therapies

Mechanistically, the activation of the KP in antigenpresenting cells, particularly the dendritic cells, is believed to promote an immunosuppressive microenvironment for the $\mathrm{T}$ cells through the combined effects of KP metabolites accumulation and TRP depletion, as shown in Figure 3. First, the activation of IDO in dendritic cells and subsequent production of KYN were found to promote the generation of Tregs from naïve T cells [88-90], while blocking their conversions to pro-inflammatory Th17-like phenotypes [91, 92]. Second, the increase in proapoptotic KP metabolites such as 3-HAA and QUIN may directly induce apoptosis in the activated T cells [93, 94]. Third, the depletion of TRP from the local environment may inhibit T-cell proliferation [95] and sensitize $\mathrm{T}$ cells to apoptosis [96].

Interestingly, experimental studies suggest that IDO activation may be a secondary mechanism that contributes in part to the therapeutic effects of T-cell costimulation blocker Cytotoxic T lymphocyte-associated antigen-4-immunoglobulin (CTLA-4-Ig) and its 2 commercially available drugs - abatacept and belatacept. The inhibition of IDO using either 1-MT or gene-knockout was shown to abrogate the immunosuppressive effects of CTLA-4-Ig in various animal models of organ and tissue transplants [97-100]. Abatacept was found to block rheumatoid factor-mediated cytokine production in human macrophages in an IDO-dependent manner in vitro [101]. CTLA-4-induced activation of IDO/TRP pathway was shown to inhibit osteoclast differentiation [102], which may explain the improvement of bone mineral density observed in rheumatoid arthritis patients taking abatacept [103]. Patients receiving belatacept showed greater amounts of peripheral blood CD16+/IDO+ cells and Tregs on graft biopsies than those under cyclosporine treatment [104, 105]. Notably, abatacept has been approved by FDA for the treatment of rheumatoid arthritis [106], while belatacept has been approved by FDA for use as an immunosuppressive therapy to prevent kidney allograft rejection [107]. Additionally, several case reports showed abatacept to have mixed success in the treatment of glomerular diseases such as minimal change disease $[108,109]$ and focal segmental glomerulosclerosis [110-113]. A phase II trial is currently underway to evaluate the use of abatacept in adults and children with minimal change disease and focal segmental glomerulosclerosis [114]. Together, these promising results highlight the relevance of IDO and KP activation in immunosuppression.

\section{KP in Blood Pressure Control}

The most well-studied KP metabolite for blood pressure control is KYNA, which was shown to be a hypotensive agent acting in the central nervous system [115]. The site of action for KYNA was localized to rostral ventrolateral medulla (RVLM), also known as the vasomotor center of the brain [116]. Microinjection of KYNA into RVLM reduced blood pressure in rat models of renovascular hypertension [117-119] and polycystic kidney disease [120]. Interestingly, the blood pressure-lowering effects of KYNA were blunted in rats pretreated with captopril [118] or with overexpression of ACE2 in the RVLM [121]. This suggests that the blood pressure-lowering effects of KYNA may involve interactions among central renin-angiotensin-aldosterone system, RVLM, and its sympathetic outflow, but the exact pathway requires further elucidation. XA was reported to possess vasodilating effects and plays a role in inflammation-induced hypotension [122], although its effects on blood pressure control in CKD have not been studied. Additionally, 2 XA derivatives demonstrated natriuretic effects $[123,124]$. Further studies are warranted to examine whether KYNA and XA can alter CKD pathogenesis and progression by regulating blood pressure.

\section{KP Metabolites as Uremic Solutes in Advanced Stages of CKD and ESKD}

In 2003, the European Uremic Toxin Work Group defined 90 compounds as uremic retention solutes [125, $126]$. Based on their chemical and protein-binding properties, they are divided into 3 categories: water-soluble, low-molecular-weight compounds ( $<500 \mathrm{Da})$, large-molecular-weight compounds (500-5,000 Da), and proteinbound compounds $[125,126]$. KP metabolites such as KYN, KYNA, and QUIN were included in the list as protein-bound compounds. The concentrations of KYNA 
[127] and QUIN [125] were reported to be 27.6 times and 15 times higher in uremic stage compared to normal renal function, respectively. Interestingly, the net clearance of KYNA was strongly associated with underlying causes of CKD $[128,129]$, indicating that the etiologies of CKD may differentially impact the proximal tubular secretory pathway. Currently, it remains a challenge to remove protein-bound uremic solutes in uremic/ESKD patients by conventional dialysis. This may explain why KYN, KYNA, and QUIN were found to remain elevated in uremic/ ESKD patients in spite of dialysis [126, 130-133]. In studies that evaluated dialysis efficiency, KP metabolites including KYN and KYNA were considered as markers for protein-bound uremic solutes. However, these markers are not currently available in routine clinical practice. This suggests that KP metabolites may be explored as potential biomarkers for protein-bound solutes to assess dialysis adequacy in uremic/ESKD patients. Currently, the analytical methods for measuring KP metabolites in human samples include mass spectrometry, high performance-liquid chromatography, and colorimetric methods [134-137], as summarized in online supplementary Table 1 (see www.karger.com/doi/10.1159/000519811 for all online suppl. material). Further development of high-throughput analytical platforms including enzymatic methods [136] may hold promise for the clinical adoption of KP metabolites as biomarkers for monitoring of CKD.

\section{KP Metabolites and Vascular Complications of Advanced CKD and ESKD}

The role of the KP in various $\mathrm{CKD}$ complications has been reviewed elsewhere [138]. Here, we briefly discuss the role of KP metabolites in thrombosis and atherosclerosis. CKD is known to increase the risk of thrombosis by at least 2-fold [139], while the uremic state accelerates the development of atherosclerosis [140]. According to Virchow's triad, hypercoagulability and atherosclerosis are important factors for thrombus formation [141], and they contribute to the prothrombotic condition in CKD patients $[142,143]$.

KP metabolites have been associated with hypercoagulability in CKD patients. Cross-sectional studies of CKD patients consistently showed positive correlations between KP metabolites such as KYN, 3-HK, and QUIN and hemostatic mediators such as von Willebrand factor $[144,145]$, tissue factor $[146,147]$, and prothrombin factor $1+2$ [146]. A longitudinal study found that CKD patients who developed arteriovenous thrombosis within a 6-week period after arteriovenous fistula creation had higher baseline KYN and tissue factor than those without thrombosis [148]. By contrast, the association of KP metabolites with fibrinolysis is less clear. One study showed that 3-HK and QUIN were positively correlated with plasmin-antiplasmin complexes in ESKD patients with hyperfibrinolysis [149]. Another study showed that ANA was positively correlated with urokinase-type plasminogen activator in the early stages of CKD, whereas it was inversely related to tissue plasminogen activator and plasminogen activator inhibitor- 1 in advanced stages of $\mathrm{CKD}$ [150]. The mixed findings on the correlation between KP metabolites and fibrinolysis markers may reflect the complex derangements of the fibrinolytic system in the settings of CKD, which is influenced by upstream mechanisms including hypercoagulation, renal damage, and inflammation.

KP metabolites have also been associated with atherosclerosis and vascular inflammation in CKD patients. Cross-sectional studies of patients with ESKD consistently showed KP metabolites such as KYN, 3-HK, and QUIN to be positively correlated with intima-media thickness and inflammatory markers $[145,151]$. An increase in the KYN/TRP ratio was found to be associated with larger carotid plaques, decreased ankle-brachial pressure index, and increased carotid artery intima-media thickness and inflammation in hemodialysis patients [152]. In 2 crosssectional studies on uremic patients, KP metabolites such as KYN, KYNA, and ANA were shown to be positively correlated with soluble forms of intercellular adhesion molecule- 1 and vascular cell adhesion protein-1 (VCAM1) $[145,153]$, which are indicative of vascular inflammation.

Despite findings from these correlational studies, our present understanding of the role of the KP in vascular disease is largely extrapolated from studies in non-CKD models [154], which suggest that the KP and its metabolites may play a protective, anti-inflammatory role in atherosclerosis. For example, in atherosclerosis-prone ApoE $(-/-)$ mice, the inhibition of IDO, either through IDO gene deletion [155] or pharmacologically using 1-MT [156], was found to accelerate atherosclerotic plaque development and worsen vascular inflammation (i.e., higher VCAM-1 expression, elevated pro-inflammatory cytokines, increased CD68 + macrophage infiltration). These changes were ameliorated by either an orally active synthetic derivative of ANA [155] or administration of 3-HAA [156]. Conversely, activation of the IDO/Tregs axis by tolerogenic dendritic cells in hyperlipidemic mice led to increased levels of KYN in atherosclerotic plaques, reduced atherosclerosis, and reduced vascular inflam- 
mation (i.e., lower VCAM-1 expression, lower CD68 + macrophage infiltration) [157]. On the other hand, KP metabolites may promote thrombosis due to their aryl hydrocarbon receptor (AhR) agonist activities. In a murine model of post-vascular injury thrombosis, the exogenous administration of KYN was found to worsen thrombosis in an AhR-dependent manner [148]. It should be noted that these data on KP metabolites and atherosclerosis or thrombosis in non-CKD settings may not extrapolate well to the CKD population. Given that KP metabolites have been associated with several important biological pathways (e.g., AhR agonist activities, immunosuppressive activities), it is reasonable to postulate that the KP also plays an important role in vascular complications in the setting of CKD. The exact role of the KP in CKD-related vascular abnormalities warrants further study.

Perspective on the Role of the KP in Dysbiosis and Microbe-Host Interactions

CKD Is Associated with Dysbiosis

Increasing evidence suggests that dysbiosis (microbiota dysregulation) may perpetuate CKD and its underlying inflammation. CKD-related factors such as accumulation of intestinal urea, diet restriction, and frequent antibiotic usage are believed to alter microbiota composition and cause dysbiosis in CKD patients [158-160]. Dysbiosis in CKD is often characterized by an overgrowth of pathobionts from the Enterobacteriaceae family and decrease of symbionts from the Bifidobacteriaceae and Lactobacillaceae families [161-164]. This is believed to promote a pro-inflammatory intestinal microenvironment $[165,166]$. The ensuing vicious cycle of local intestinal inflammation and increased epithelial barrier dysfunction ("leaky gut") enables endotoxins and microbial metabolites to translocate into the host's bloodstream, contributing to systemic inflammation in CKD patients [167, 168]. In addition, the accumulation of microbial-derived metabolites such as indoxyl sulfate in the bloodstream is believed to increase cardiovascular and renal toxicity in CKD patients [160, 169]. In view of this, researchers have explored the therapeutic use of probiotics containing $B i$ fidobacteria and Lactobacillus species in CKD patients, and these probiotics have been shown to significantly reduce inflammation and improve renal functions [170174].

KP Is Altered by the Gut Microbiota

The key role of the gut microbiota in stimulating IDO and activating the KP was demonstrated in several stud- ies. Germ-free mice showed lower KYN/TRP ratio compared to conventional mice [175]. This trend was reversed by the colonization of germ-free mice with conventional mice fecal microbiota [176]. The IDO expression in the colon and immune cells were generally upregulated in the presence of gut bacteria from the genera Bifidobacteria, Lactobacillus, Bacillus, and Clostridium [177-182], though specific species such as Lactobacillus johnsonii showed inhibitory effects [183]. In terms of microbe-host dynamics, the prevailing view from these studies is that the microbes and their components may stimulate host IDO enzyme, leading to an upregulation of the KP and its metabolites in the host body. For example, the exopolysaccharide from Bacillus subtilis was found to induce IDO in host dendritic cells [182]. Interestingly, an in vivo study using a CKD rat model reported a positive correlation between the plasma KP metabolites (KYN and 3-HK) and gut bacteria from the genera Oscillibacter, Blautia, and Intestinimonas. These gut bacteria were predicted to possess IDO genes using PICRUSt database based on ancestral state reconstruction. This suggests that the gut bacteria may play a key role by directly producing KP metabolites. However, one has to be cautious when interpreting bacterial genes of the KP enzymes. While the KP is the primary de novo pathway for NAD+ synthesis in eukaryotes and their enzymes are constitutively expressed in mammals, most bacteria depend instead on the aspartate pathway for de novo NAD+ synthesis and their KP-related genes may play a lesser role compared to mammals $[184,185]$. Indeed, a study found that the catalytic efficiencies of IDO in certain bacteria were much lower than their mammalian homologs and are unlikely to contribute to TRP metabolism [186]. Further experiments are required to ascertain whether gut bacteria from genera Oscillibacter, Blautia, and Intestinimonas can produce substantial amount of the KP metabolites. By extension, further work is also needed to delineate the specific contribution of microbe and the host cells for the production of the KP metabolites during CKD-related dysbiosis.

KP Modulates Host Immunity and Microbiota Composition, Which May Indirectly Affect CKD

Pathogenesis and Progression

The interaction between gut microbiota and host immune system is multifaceted [187]. Functionally, the KP was found to be a key player in mediating the microbehost immunity interplay. The activation of the KP via IDO was crucial for mediating the immunomodulatory effects of symbionts Bifidobacteria and Lactobacillus spe- 
cies in models of inflammatory and allergic diseases such as ulcerative colitis [177, 181], rheumatoid arthritis [177], atopic dermatitis [177], allergic asthma [188], and autoimmune Type 1 diabetes [179]. In these studies, supplementation with probiotics containing these 2 symbionts led to an upregulation of IDO expression or increase in $\mathrm{KYN} / \mathrm{TRP}$ ratio, reduction of inflammation, and alleviation of disease severity. Mechanistically, the protective effects conferred by the probiotics involved the modulation of Tregs/Th17 balance via an upregulation of IDO in immune cells such as dendritic cells [177, 179, 181, 189]. Interestingly, a study highlighted IDO-dependent expansion of Tregs in the intestinal mucosa as an important aspect of microbe-host crosstalk during development and may be associated with resistance against inflammatory and allergic diseases later in adulthood [178]. Moreover, Lactobacillus-induced elevation of KYN in the gut epithelium was found to increase Type 3 innate lymphoid cells, a specialized gut immune cell required for the maintenance of gut mucosal homeostasis [190]. KYN was also found to protect against colitis by reducing intestinal permeability and promoting epithelial wound healing [191]. Collectively, these studies suggest that the KP and its metabolites may be key mediators of the host-microbe symbiosis that maintains gut and systemic immunity. Further work is required to validate these findings in CKD settings.

The relationship between the gut microbes and hosts is bidirectional. Besides influencing host immunity, the activation of the KP may modulate certain TRP-metabolizing bacteria. The activation of the KP was shown to limit TRP availability and reduce indole-producing bacteria and their metabolites, such as indoxyl sulfate [192] and indole-3-acetic acid [193, 194]. The effects of indole metabolites in CKD have been reviewed elsewhere [195198]. Currently, the carbonaceous adsorbent AST-120 is used to reduce indoxyl sulfate production in CKD patients [199]. The activation of the KP may represent another strategy to reduce indole metabolites in CKD patients.

\section{Conclusion}

The KP is the major pathway for TRP catabolism. During inflammation, the activation of the KP via its ratelimiting enzyme IDO is driven by pro-inflammatory cytokines such as IFN- $\gamma$ and TNF- $\alpha$. Given that immune activation and the resultant elevation of pro-inflammatory cytokines underlie the pathogenesis and progression of
$\mathrm{AKI}$ and $\mathrm{CKD}$, it is not unexpected to see that the $\mathrm{KP}$ is activated in clinical and animal studies of these diseases. KP metabolites are currently being explored as early biomarkers for AKI and uremic markers for adequacy of dialysis in ESKD patients. Since the turnover of KP metabolites such as KYNA is highly determined by tubular excretion, they may serve as promising biomarkers for tubular function, to complement glomerular filtration markers currently used in diagnosis and prognosis of kidney diseases.

The therapeutic potential of the KP in kidney diseases warrants future research. Activation of the KP is often regarded as a counter-regulatory mechanism to inflammation. Thus, the KP is found to confer protection in kidney diseases where inflammation is the primary insult. In vivo studies consistently demonstrated a protective role for the KP and its metabolites in various models of glomerulonephritis by slowing T-cell proliferation and reducing activation of pro-inflammatory $\mathrm{T}$-cell phenotypes (Th1 and Th17), while enhancing the switch to immunosuppressive T-cell phenotypes (Th2 and Tregs). Interestingly, some studies have demonstrated that shunting the KP toward certain side branches can confer significant protection against AKI. This may be a possible approach to exploit the renoprotective effects of specific components of KP.

Besides immunomodulatory activity, KP metabolites possessed other biological functions, including hypotensive, antioxidant, and AhR agonist effects. Given the complexities of kidney diseases and multi-organ involvement in CKD complications, the interpretation of the biologic activities of KP metabolites may be context-dependent and should be done with caution. Further loss-offunction/gain-of-function studies are needed to tease apart how individual metabolites contribute to and alter the course of kidney diseases and their complications. The role of the KP in CKD-related dysbiosis also warrants further research.

This review contextualizes the role of the KP and its metabolites in AKI and CKD. Emerging data support the $\mathrm{KP}$ and its metabolites as promising candidates for developing relevant biomarkers and targeted therapies for these kidney diseases.

\section{Conflict of Interest Statement}

The authors have no conflicts of interest to declare. 


\section{Funding Sources}

Dr. S.C. Lim was funded by the Singapore National Medical Research Council (CSA-INV/0020/2017). Dr. J.-J. Liu acknowledges funding support from KTPH STAR 20201.

\section{Author Contributions}

H.N.W. wrote the first draft and edited the manuscript. J.-J.L., J.C., J.P.K., and S.C.L. were responsible for conceptualization, critical review, and editing of the manuscript. All authors have read and approved the final manuscript.

\section{References}

1 Mehta RL, Cerdá J, Burdmann EA, Tonelli M, García-García G, Jha V, et al. International society of nephrology's 0 by 25 initiative for acute kidney injury (zero preventable deaths by 2025): a human rights case for nephrology. Lancet. 2015;385(9987):2616-43.

2 Hoste EAJ, Kellum JA, Selby NM, Zarbock A, Palevsky PM, Bagshaw SM, et al. Global epidemiology and outcomes of acute kidney injury. Nat Rev Nephrol. 2018;14(10):607-25.

3 Sawhney S, Fraser SD. Epidemiology of AKI: utilizing large databases to determine the burden of AKI. Adv Chronic Kidney Dis. 2017 Jul;24(4):194-204.

4 Carney EF. The impact of chronic kidney disease on global health. Nat Rev Nephrol. 2020; 16(5):251-1.

5 Cervenka I, Agudelo LZ, Ruas JL. Kynurenines: tryptophan's metabolites in exercise, inflammation, and mental health. Science. 2017;357(6349):eaaf9794.

6 Schwarcz R, Bruno JP, Muchowski PJ, Wu HQ. Kynurenines in the mammalian brain: when physiology meets pathology. Nat Rev Neurosci. 2012;13(7):465-77.

7 Savitz J. The kynurenine pathway: a finger in every pie. Mol Psychiatry. 2020;25(1):131-47.

8 Polyzos KA, Ketelhuth DF. The role of the kynurenine pathway of tryptophan metabolism in cardiovascular disease. An emerging field. Hamostaseologie. 2015;35(02):128-36.

9 Al Saedi A, Sharma S, Summers MA, Nurgali $\mathrm{K}$, Duque $\mathrm{G}$. The multiple faces of tryptophan in bone biology. Exp Gerontol. 2020;129: 110778.

10 Badawy AA. Tryptophan metabolism: a versatile area providing multiple targets for pharmacological intervention. Egypt J Basic Clin Pharmacol. 2019;9:10.

11 Cervenka I, Agudelo LZ, Ruas JL. Kynurenines: tryptophan's metabolites in exercise, inflammation, and mental health. Science. 2017;357(6349):eaaf9794.

12 Pucci L, Perozzi S, Cimadamore F, Orsomando G, Raffaelli N. Tissue expression and biochemical characterization of human 2-amino 3-carboxymuconate 6-semialdehyde decarboxylase, a key enzyme in tryptophan catabolism. FEBS J. 2007 Feb;274(3):827-40.

13 Castro-Portuguez R, Sutphin GL. Kynurenine pathway, NAD+ synthesis, and mitochondrial function: targeting tryptophan metabolism to promote longevity and healthspan. Exp Gerontol. 2020;132:110841.

14 Robinson CM, Hale PT, Carlin JM. The role of IFN- $\gamma$ and TNF- $\alpha$-responsive regulatory elements in the synergistic induction of in- doleamine dioxygenase. J Interferon Cytokine Res. 2005;25(1):20-30.

15 O'Connor JC, André C, Wang Y, Lawson MA, Szegedi SS, Lestage J, et al. Interferon- and tumor necrosis factor mediate the upregulation of indoleamine 2,3-dioxygenase and the induction of depressive-like behavior in mice in response to bacillus calmette-guerin. J Neurosci. 2009;29(13):4200-9.

16 Wirthgen E, Hoeflich A, Rebl A, Günther J. Kynurenic acid: the janus-faced role of an immunomodulatory tryptophan metabolite and its link to pathological conditions. Front Immunol. 2018;8(1957):1957.

17 Mándi Y, Vécsei L. The kynurenine system and immunoregulation. J Neural Transm. 2012;119(2):197-209.

18 Zulpaite R, Miknevicius P, Leber B, Strupas K, Stiegler P, Schemmer P. Tryptophan metabolism via kynurenine pathway: role in solid organ transplantation. Int J Mol Sci. 2021;22(4): 1921.

19 Mellor AL, Lemos H, Huang L. Indoleamine 2,3-dioxygenase and tolerance: where are we now? Front Immunol. 2017;8:1360-0.

$20 \mathrm{Wu} \mathrm{H}$, Gong J, Liu Y. Indoleamine 2, 3-dioxygenase regulation of immune response (Review). Mol Med Rep. 2018;17(4):4867-73.

21 Devarajan P. Update on mechanisms of ischemic acute kidney injury. J Am Soc Nephrol. 2006;17(6):1503.

22 Rahman M, Shad F, Smith MC. Acute kidney injury: a guide to diagnosis and management. Am Fam Physician. 2012;86(7):631-9.

23 Tao Li PK, Burdmann EA, Mehta RL. Acute kidney injury: global health alert. Kidney Int. 2013;20(2):114-7.

24 Cerdá J, Liu KD, Cruz DN, Jaber BL, Koyner JL, Heung M, et al. Promoting kidney function recovery in patients with AKI requiring RRT. Clin J Am Soc Nephrol. 2015 Oct 7; 10(10):1859-67.

25 Zheng X, Zhang A, Binnie M, McGuire K, Webster SP, Hughes J, et al. Kynurenine 3 -monooxygenase is a critical regulator of renal ischemia-reperfusion injury. Exp Mol Med. 2019 Feb 13;51(2):1-14

26 Wei Q, Xiao X, Fogle P, Dong Z. Changes in metabolic profiles during acute kidney injury and recovery following Ischemia/Reperfusion. PloS One. 2014;9(9):e106647.

27 Iwaki T, Bennion BG, Stenson EK, Lynn JC, Otinga C, Djukovic D, et al. PPAR $\alpha$ contributes to protection against metabolic and inflammatory derangements associated with acute kidney injury in experimental sepsis. Physiol Rep. 2019 May;7(10):e14078.
28 Standage SW, Xu S, Brown L, Ma Q, Koterba A, Lahni P, et al. NMR-based serum and urine metabolomic profile reveals suppression of mitochondrial pathways in experimental sepsis-associated acute kidney injury. Am J Physiol Renal Physiol. 2021;320(5):F984F1000.

29 Zgoda-Pols JR, Chowdhury S, Wirth M, Milburn MV, Alexander DC, Alton KB. Metabolomics analysis reveals elevation of 3-indoxyl sulfate in plasma and brain during chemically-induced acute kidney injury in mice: investigation of nicotinic acid receptor agonists. Toxicol Appl Pharmacol. 2011 Aug 15;255(1): 48-56.

30 Volarevic V, Markovic BS, Jankovic MG Djokovic B, Jovicic N, Harrell CR, et al. Galectin 3 protects from cisplatin-induced acute kidney injury by promoting TLR-2-dependent activation of IDO1/Kynurenine pathway in renal DCs. Theranostics. 2019;9(20):59766001.

31 Hanna MH, Segar JL, Teesch LM, Kasper DC, Schaefer FS, Brophy PD. Urinary metabolomic markers of aminoglycoside nephrotoxicity in newborn rats. Pediatr Res. 2013 May; 73(5):585-91.

32 Abstracts33rd International Winter WorkshopClinical. Chemical and biochemical aspects of pteridines and related topics. Pteridines. 2014;25(1):11-31.

33 Rabb H, Griffin MD, McKay DB, Swaminathan S, Pickkers P, Rosner MH, et al. Inflammation in AKI: current understanding, key questions, and knowledge gaps. J Am Soc Nephrol. 2016;27(2):371-9.

34 Tran MT, Zsengeller ZK, Berg AH, Khankin EV, Bhasin MK, Kim W, et al. PGC1 $a$ drives NAD biosynthesis linking oxidative metabolism to renal protection. Nature. 2016; 531(7595):528-32.

35 Poyan Mehr A, Tran MT, Ralto KM, Leaf DE, Washco V, Messmer J, et al. De novo NAD+ biosynthetic impairment in acute kidney injury in humans. Nat Med. 2018;24(9):1351-9.

36 Zhang F, Wang Q, Xia T, Fu S, Tao X, Wen Y, et al. Diagnostic value of plasma tryptophan and symmetric dimethylarginine levels for acute kidney injury among tacrolimus-treated kidney transplant patients by targeted metabolomics analysis. Sci Rep. 2018;8(1):14688.

37 Dabrowski W, Kocki T, Pilat J, Parada-Turska J, Malbrain ML. Changes in plasma kynurenic acid concentration in septic shock patients undergoing continuous veno-venous haemofiltration. Inflammation. $2014 \mathrm{Feb} ; 37(1): 223$ 34. 
38 Aregger F, Uehlinger DE, Fusch G, Bahonjic A, Pschowski R, Walter M, et al. Increased urinary excretion of kynurenic acid is associated with non-recovery from acute kidney injury in critically ill patients. BMC Nephrol. 2018 Feb 26;19(1):44.

39 Bhatraju PK, Chai XY, Sathe NA, Ruzinski J, Siew ED, Himmelfarb J, et al. Assessment of kidney proximal tubular secretion in critical illness. JCI insight. 2021;6(10):e145514.

40 Bajaj JS, Garcia-Tsao G, Reddy KR, O’Leary JG, Vargas HE, Lai JC, et al. Admission urinary and serum metabolites predict renal outcomes in hospitalized patients with cirrhosis. Hepatology. 2018.

41 Gilbert S, Weiner DE. National kidney foundation primer on kidney diseases e-book: Elsevier Health Sciences; 2013.

42 Mehta RL. Timed and targeted therapy for acute kidney injury: a glimpse of the future. Kidney Int. 2010;77(11):947-9.

43 Mohib K, Wang S, Guan Q, Mellor AL, Sun $\mathrm{H}, \mathrm{Du} \mathrm{C}$, et al. Indoleamine 2,3-dioxygenase expression promotes renal ischemia-reperfusion injury. Am J Physiol Renal Physiol. 2008 Jul;295(1):F226-34.

44 Pan B, Zhang H, Hong Y, Ma M, Wan X, Cao C. Indoleamine-2,3-dioxygenase activates Wnt/ $\beta$-catenin inducing kidney fibrosis after acute kidney injury. Gerontology. 2021:1.

45 Mole DJ, Webster SP, Uings I, Zheng X, Binnie $\mathrm{M}$, Wilson $\mathrm{K}$, et al. Kynurenine-3-monooxygenase inhibition prevents multiple organ failure in rodent models of acute pancreatitis. Nat Med. 2016 Feb;22(2):202-9.

46 Pundir M, Arora S, Kaur T, Singh R, Singh AP. Effect of modulating the allosteric sites of $\mathrm{n}$-methyl-d-aspartate receptors in ischemiareperfusion induced acute kidney injury. J Surg Res. 2013 Aug;183(2):668-77.

47 Arora S, Kaur T, Kaur A, Singh AP. Glycine aggravates ischemia reperfusion-induced acute kidney injury through n-methyl-d-aspartate receptor activation in rats. Mol Cell Biochem. 2014 Aug;393(1-2):123-31.

48 Mohib K, Guan Q, Diao H, Du C, Jevnikar AM. Proapoptotic activity of indoleamine 2,3-dioxygenase expressed in renal tubular epithelial cells. Am J Physiol Renal Physiol. 2007;293(3):F801-12.

49 Wilson K, Auer M, Binnie M, Zheng X, Pham NT, Iredale JP, et al. Overexpression of human kynurenine-3-monooxygenase protects against 3-hydroxykynurenine-mediated apoptosis through bidirectional nonlinear feedback. Cell Death Dis. 2016 Apr 14;7(4):e2197.

50 Katsyuba E, Mottis A, Zietak M, De Franco F, van der Velpen V, Gariani K, et al. De novo $\mathrm{NAD}(+)$ synthesis enhances mitochondrial function and improves health. Nature. 2018; 563(7731):354-9.

51 Massudi H, Grant R, Guillemin GJ, Braidy N. $\mathrm{NAD}+$ metabolism and oxidative stress: the golden nucleotide on a crown of thorns. Redox Rep. 2012;17(1):28-46.

52 Martin DR, Lewington AJ, Hammerman MR, Padanilam BJ. Inhibition of poly (ADP-ri- bose) polymerase attenuates ischemic renal injury in rats. Am J Physiol Renal Physiol. 2000;279(5):R1834-R40.

53 Bao YS, Ji Y, Zhao SL, Ma LL, Xie RJ, Na SP. Serum levels and activity of indoleamine2,3dioxygenase and tryptophanyl-tRNA synthetase and their association with disease severity in patients with chronic kidney disease. Biomarkers. 2013 Aug;18(5):379-85.

54 Pan B, Zhang F, Sun J, Chen D, Huang W, Zhang $\mathrm{H}$, et al. Correlation of indoleamine-2,3-dioxygenase and chronic kidney disease: a pilot study. J Immunol Res. 2021; 2021:8132569.

55 Rhee EP, Clish CB, Ghorbani A, Larson MG, Elmariah S, McCabe E, et al. A combined epidemiologic and metabolomic approach improves CKD prediction. J Am Soc Nephrol. 2013 Jul;24(8):1330-8.

56 Goek ON, Prehn C, Sekula P, Römisch-Margl W, Döring A, Gieger C, et al. Metabolites associate with kidney function decline and incident chronic kidney disease in the general population. Nephrol Dial Transplant. 2013 Aug;28(8):2131-8.

57 Lee H, Jang HB, Yoo MG, Park SI, Lee HJ. Amino acid metabolites associated with chronic kidney disease: an eight-year followup korean epidemiology study. Biomedicines. 2020 Jul 17;8(7):222.

58 Silva RE, Baldim JL, Chagas-Paula DA, Soares MG, Lago JHG, Gonçalves RV, et al. Predictive metabolomic signatures of end-stage renal disease: a multivariate analysis of population-based data. Biochimie. 2018 Sep;152: 14-30.

59 Brand JA, Mutsaers HA, ADv Z, Blankestijn PJ, Broek PHH, Russel FGM, et al. Uremic solutes in chronic kidney disease and their role in progression. PLoS One. 2016;11(12): e0168117.

60 Chen Y, Zelnick LR, Wang K, Hoofnagle AN, Becker JO, Hsu CY, et al. Kidney clearance of secretory solutes is associated with progression of CKD: the CRIC study. J Am Soc Nephrol. 2020 Apr;31(4):817-27.

61 Debnath S, Velagapudi C, Redus L, Thameem F, Kasinath B, Hura CE, et al. Tryptophan metabolism in patients with chronic kidney disease secondary to type 2 diabetes: relationship to inflammatory markers. Int J Tryptophan Res. 2017;10:1178646917694600.

62 Zhang Y, Ruan Y, Zhang P, Wang L. Increased indoleamine 2,3-dioxygenase activity in type 2 diabetic nephropathy. J Diabetes Complications. 2017 Jan;31(1):223-7.

63 Cernaro V, Loddo S, Macaione V, Ferlazzo VT, Cigala RM, Crea F, et al. RAS inhibition modulates kynurenine levels in a CKD population with and without type 2 diabetes mellitus. Int Urol Nephrol. 2020 Jun;52(6):112533.

$64 \mathrm{Wu} \mathrm{MH}$, Lin CN, Chiu DT, Chen ST. Kynurenine/tryptophan ratio predicts angiotensin receptor blocker responsiveness in patients with diabetic kidney disease. Diagnostics. 2020 Apr 9;10(4):207.
65 Hirayama A, Nakashima E, Sugimoto M, Akiyama S, Sato W, Maruyama S, et al. Metabolic profiling reveals new serum biomarkers for differentiating diabetic nephropathy. Anal Bioanal Chem. 2012 Dec;404(10):3101-9.

66 Winther SA, Henriksen P, Vogt JK, Hansen TH, Ahonen L, Suvitaival T, et al. Gut microbiota profile and selected plasma metabolites in type 1 diabetes without and with stratification by albuminuria. Diabetologia. 2020 Sep 4 .

67 van der Kloet FM, Tempels FW, Ismail N, van der Heijden R, Kasper PT, Rojas-Cherto M, et al. Discovery of early-stage biomarkers for diabetic kidney disease using ms-based metabolomics (FinnDiane study). Metabolomics. 2012;8(1):109-19.

68 Baban B, Liu JY, Mozaffari MS. Endoplasmic reticulum stress response and inflammatory cytokines in type 2 diabetic nephropathy: role of indoleamine 2,3-dioxygenase and programmed death-1. Exp Mol Pathol. 2013; 94(2):343-51.

69 Yu K, Li D, Xu F, Guo H, Feng F, Ding Y, et al. IDO1 as a new immune biomarker for diabetic nephropathy and its correlation with immune cell infiltration. Int Immunopharmacol. 2021;94:107446.

70 Øvrehus MA, Bruheim P, Ju W, Zelnick LR, Langlo KA, Sharma K, et al. Gene expression studies and targeted metabolomics reveal disturbed serine, methionine, and tyrosine metabolism in early hypertensive nephrosclerosis. Kidney Int Rep. 2019;4(2):321-33.

71 Bartosiewicz J, Kaminski T, Pawlak K, Karbowska M, Tankiewicz-Kwedlo A, Pawlak D. The activation of the kynurenine pathway in a rat model with renovascular hypertension. Exp Biol Med. 2017 Apr;242(7):750-61.

72 Martinsons A, Rudzite V, Groma V, Bratslavska O, Widner B, Fuchs D. Kynurenine and neopterin in chronic glomerulonephritis. Adv Exp Med Biol. 1999;467:579-86.

73 Kalantari S, Nafar M, Samavat S, Parvin M. 1 H NMR-based metabolomics study for identifying urinary biomarkers and perturbed metabolic pathways associated with severity of IgA nephropathy: a pilot study. Magn Reson Chem. 2017;55(8):693-9.

74 Hou W, Li S, Wu Y, Du X, Yuan F. Inhibition of indoleamine 2, 3-dioxygenase-mediated tryptophan catabolism accelerates crescentic glomerulonephritis. Clin Exp Immunol. 2009 May;156(2):363-72.

75 Vanholder R, Fouque D, Glorieux G, Heine GH, Kanbay M, Mallamaci F, et al. Clinical management of the uraemic syndrome in chronic kidney disease. Lancet Diabetes Endocrinol. 2016;4(4):360-73.

76 Schefold JC, Zeden JP, Fotopoulou C, von Haehling S, Pschowski R, Hasper D, et al. Increased indoleamine 2,3-dioxygenase (IDO) activity and elevated serum levels of tryptophan catabolites in patients with chronic kidney disease: a possible link between chronic inflammation and uraemic symptoms. Nephrol Dial Transplant. 2009 Jun;24(6): 1901-8. 
77 Pawlak K, Kowalewska A, Mysliwiec M, Pawlak D. 3-hydroxyanthranilic acid is independently associated with monocyte chemoattractant protein-1 (CCL2) and macrophage inflammatory protein-1beta (CCL4) in patients with chronic kidney disease. Clin Biochem. 2010 Sep;43(13-14):1101-6.

78 Kalim S, Clish CB, Deferio JJ, Ortiz G, Moffet AS, Gerszten RE, et al. Cross-sectional examination of metabolites and metabolic phenotypes in uremia. BMC Nephrol. 2015;16(1): 98.

79 Hou W, Huang G, Cao X, Zhang Y, Zhang J, Li Y. Suppression of experimental autoimmune glomerulonephritis by tryptophan. J Nephrol. 2014 Feb;27(1):19-28.

80 Yang Y, Liu K, Chen Y, Gong Y, Liang Y. Indoleamine 2,3-dioxygenase (IDO) regulates Th17/Treg immunity in experimental IgA nephropathy. Folia Biol. 2019;65(2):101-8.

81 Liu K, Yang Y, Chen Y, Li S, Gong Y, Liang Y. The therapeutic effect of dendritic cells expressing indoleamine 2,3-dioxygenase (IDO) on an IgA nephropathy mouse model. Int Urol Nephrol. 2020;52(2):399-407.

82 Chaudhary K, Shinde R, Liu H, GnanaPrakasam JP, Veeranan-Karmegam R, Huang $\mathrm{L}$, et al. Amino acid metabolism inhibits antibody-driven kidney injury by inducing autophagy. J Immunol. 2015;194(12):5713-24.

83 Clement CC, D'Alessandro A, Thangaswamy S, Chalmers S, Furtado R, Spada S, et al. 3-hydroxy-L-kynurenamine is an immunomodulatory biogenic amine. Nat Commun. 2021; 12(1):4447.

84 Matheus LHG, Simão GM, Amaral TA, Brito RBO, Malta CS, Matos YST, et al. Indoleamine 2, 3-dioxygenase (IDO) increases during renal fibrogenesis and its inhibition potentiates TGF- $\beta$ 1-induced epithelial to mesenchymal transition. BMC nephrology. 2017; 18(1):287-7.

85 Zhang ZH, He JQ, Qin WW, Zhao YY, Tan $\mathrm{NH}$. Biomarkers of obstructive nephropathy using a metabolomics approach in rat. Chem Biol Interact. 2018;296:229-39.

86 Chen L, Chen DQ, Liu JR, Zhang J, Vaziri ND, Zhuang S, et al. Unilateral ureteral obstruction causes gut microbial dysbiosis and metabolome disorders contributing to tubulointerstitial fibrosis. Exp Mol Med. 2019;51(3):1-18.

87 Liu Y. Cellular and molecular mechanisms of renal fibrosis. Nat Rev Nephrol. 2011 Oct 18; 7(12):684-96.

88 Fallarino F, Grohmann U, You S, McGrath BC, Cavener DR, Vacca C, et al. The combined effects of tryptophan starvation and tryptophan catabolites down-regulate $\mathrm{T}$ cell receptor zeta-chain and induce a regulatory phenotype in naive T cells. J Immunol. 2006 Jun 1;176(11):6752-61.

89 Chen W, Liang X, Peterson AJ, Munn DH, Blazar BR. The indoleamine 2,3-dioxygenase pathway is essential for human plasmacytoid dendritic cell-induced adaptive $\mathrm{T}$ regulatory cell generation. J Immunol. 2008;181(8): 5396-404.
90 Mezrich JD, Fechner JH, Zhang X, Johnson BP, Burlingham WJ, Bradfield CA. An interaction between kynurenine and the aryl hydrocarbon receptor can generate regulatory T cells. J Immunol. 2010;185(6):3190-8.

91 Baban B, Chandler PR, Sharma MD, Pihkala J, Koni PA, Munn DH, et al. IDO activates regulatory $\mathrm{T}$ cells and blocks their conversion into Th17-like T cells. J Immunol. 2009; 183(4):2475

92 Sharma MD, Hou DY, Liu Y, Koni PA, Metz $\mathrm{R}$, Chandler $\mathrm{P}$, et al. Indoleamine 2,3-dioxygenase controls conversion of Foxp3+ Tregs to TH17-like cells in tumor-draining lymph nodes. Blood. 2009;113(24):6102-11.

93 Fallarino F, Grohmann U, Vacca C, Bianchi R, Orabona C, Spreca A, et al. T cell apoptosis by tryptophan catabolism. Cell Death Differ. 2002 Oct;9(10):1069-77.

94 Belladonna ML, Grohmann U, Guidetti P, Volpi C, Bianchi R, Fioretti MC, et al. Kynurenine pathway enzymes in dendritic cells initiate tolerogenesis in the absence of functional IDO. J Immunol. 2006;177(1):130-7.

95 Munn DH, Sharma MD, Baban B, Harding HP, Zhang Y, Ron D, et al. GCN2 kinase in $T$ cells mediates proliferative arrest and anergy induction in response to indoleamine 2,3-dioxygenase. Immunity. 2005;22(5): 633-42.

96 Lee GK, Park HJ, Macleod M, Chandler P, Munn DH, Mellor AL. Tryptophan deprivation sensitizes activated $\mathrm{T}$ cells to apoptosis prior to cell division. Immunology. 2002 Dec;107(4):452-60.

97 Grohmann U, Orabona C, Fallarino F, Vacca C, Calcinaro F, Falorni A, et al. CTLA4-Ig regulates tryptophan catabolism in vivo. Nat Immunol. 2002;3(11):1097-101.

98 Sucher R, Fischler K, Oberhuber R, Kronberger I, Margreiter C, Ollinger R, et al. IDO and regulatory $\mathrm{T}$ cell support are critical for cytotoxic T lymphocyte-associated Ag-4 Igmediated long-term solid organ allograft survival. J Immunol. 2012;188(1):37-46.

99 Xiao B, Liu B, Song Y, Yu Z, Guo S. Local cytotoxic T-lymphocyte-associated antigen-4 immunoglobulin inhibition of rejection response is dependent on indoleamine 2,3-dioxygenase activities in the allograft. Transplant Proc. 2014;46(10):3637-40.

100 Ye QX, Xu LH, Shi PJ, Xia T, Fang JP. Indoleamine 2,3-dioxygenase and inducible nitric oxide synthase mediate immune tolerance induced by CTLA4Ig and anti-CD154 hematopoietic stem cell transplantation in a sensitized mouse model. Exp Ther Med. 2017;14(3):1884-91.

101 Bozec A, Luo Y, Engdahl C, Figueiredo C, Bang H, Schett G. Abatacept blocks anticitrullinated protein antibody and rheumatoid factor mediated cytokine production in human macrophages in IDO-dependent manner. Arthritis Res Ther. 2018;20(1):249.

102 Bozec A, Zaiss MM, Kagwiria R, Voll R, Rauh M, Chen Z, et al. T cell costimulation molecules CD80/86 inhibit osteoclast differentiation by inducing the IDO/tryptophan pathway. Sci Transl Med. 2014;6(235): 235ra60-35ra60.

103 Tada M, Inui K, Sugioka Y, Mamoto K, Okano T, Koike T. Abatacept might increase bone mineral density at femoral neck for patients with rheumatoid arthritis in clinical practice: AIRTIGHT study. Rheumatol Int. 2018;38(5):777-84.

104 Furuzawa-Carballeda J, Lima G, UribeUribe N, Avila-Casado C, Mancilla E, Morales-Buenrostro LE, et al. High levels of IDO-expressing CD16+ peripheral cells, and Tregs in graft biopsies from kidney transplant recipients under belatacept treatment. Transplan Proceed. 2010;42(9):348996.

105 Furuzawa-Carballeda J, Uribe-Uribe NO, Arreola-Guerra JM, Reyes-Acevedo R, Vilatobá M, López-Toledo A, et al. Tissue talks: immunophenotype of cells infiltrating the graft explains histological findings and the benefits of belatacept at 10 years. Clin Exp Immunol. 2019 Aug;197(2):250-61.

106 Moreland L, Bate G, Kirkpatrick P. Abatacept. Nat Rev Drug Discov. 2006;5(3):185.

107 Archdeacon P, Dixon C, Belen O, Albrecht $\mathrm{R}$, Meyer J. Summary of the US FDA approval of belatacept. Am J Transplant. 2012; 12(3):554-62.

108 Dado D, Parikh S, Ayoub I, Rovin B, Nadasdy T, Hebert L. Abatacept efficacy in steroidresistant minimal-change disease revealed by the speed of proteinuria reduction after the start of abatacept. Clin Nephrol. 2018; 89(5):376

109 Isom R, Shoor S, Higgins J, Cara-Fuentes G, Johnson RJ. Abatacept in steroid-dependent minimal change disease and CD80-uria. Kidney Int Rep. 2019;4(9):1349-53.

110 Yu CC, Fornoni A, Weins A, Hakroush S, Maiguel D, Sageshima J, et al. Abatacept in B7-1-positive proteinuric kidney disease. $\mathrm{N}$ Engl J Med. 2013;369(25):2416-23.

111 Garin EH, Reiser J, Cara-Fuentes G, Wei C, Matar D, Wang H, et al. Case series: CTLA4IgG1 therapy in minimal change disease and focal segmental glomerulosclerosis. Pediatr Nephrol. 2015;30(3):469-77.

112 Kristensen T, Ivarsen P, Povlsen JV. Unsuccessful treatment with abatacept in recurrent focal segmental glomerulosclerosis after kidney transplantation. Case Rep Nephrol Dial. 2017;7(1):1-5.

113 Hansrivijit P, Puthenpura MM, Ghahramani N. Efficacy of abatacept treatment for focal segmental glomerulosclerosis and minimal change disease: a systematic review of case reports, case series, and observational studies. Clinical Nephrology. 2020.

114 Trachtman H, Gipson DS, Somers M, Spino C, Adler S, Holzman L, et al. Randomized clinical trial design to assess abatacept in resistant nephrotic syndrome. Kidney Int Rep. 2017;3(1):115-21. 
115 Małkiewicz MA, Szarmach A, Sabisz A, Cubała WJ, Szurowska E, Winklewski PJ. Blood-brain barrier permeability and physical exercise. J Neuroinflammation. 2019; 16(1):15-6.

116 Kumagai $\mathrm{H}$, Oshima N, Matsuura T, Iigaya $\mathrm{K}$, Imai M, Onimaru H, et al. Importance of rostral ventrolateral medulla neurons in determining efferent sympathetic nerve activity and blood pressure. Hypertens Res. 2012; 35(2):132-41.

117 Martinez-Maldonado M. Pathophysiology of renovascular hypertension. Hypertension. 1991;17(5):707-19.

118 Carvalho TH, Bergamaschi CT, Lopes OU, Campos RR. Role of endogenous angiotensin II on glutamatergic actions in the rostral ventrolateral medulla in Goldblatt hypertensive rats. Hypertension. 2003 Oct;42(4): 707-12.

119 Mourão AA, de Mello ABS, Dos Santos Moreira MC, Rodrigues KL, Lopes PR, Xavier $\mathrm{CH}$, et al. Median preoptic nucleus excitatory neurotransmitters in the maintenance of hypertensive state. Brain Res Bull. 2018 Sep;142:207-15.

120 Underwood CF, Boyd R, Phillips JK, Hildreth CM. Increased excitatory regulation of the hypothalamic paraventricular nucleus and circulating vasopressin results in the hypertension observed in polycystic kidney disease. J Hypertens. 2019 Jan;37(1):109-15.

121 Wang YK, Shen D, Hao Q, Yu Q, Wu ZT, Deng Y, et al. Overexpression of angiotensin-converting enzyme 2 attenuates tonically active glutamatergic input to the rostral ventrolateral medulla in hypertensive rats. Am J Physiol Heart Circ Physiol. 2014 Jul 15; 307(2):H182-90.

122 Fazio F, Carrizzo A, Lionetto L, Damato A, Capocci L, Ambrosio M, et al. Vasorelaxing action of the kynurenine metabolite, xanthurenic acid: the missing link in endotoxininduced hypotension? Front Pharmacol. 2017;8(214):214.

123 Cain CD, Schroeder FC, Shankel SW, Mitchnick M, Schmertzler M, Bricker NS. Identification of xanthurenic acid 8-O-beta-Dglucoside and xanthurenic acid 8-O-sulfate as human natriuretic hormones. Proc Natl Acad Sci USA. 2007;104(45):17873-8.

124 Hoffman A, Okun-Gurevich M, Ovcharenko E, Goltsman I, Karram T, Cain C, et al. Renal effects of a novel endogenous natriuretic agent xanthurenic acid 8 -o- $\beta$-dglucoside in rats. Physiol Rep. 2013;1(6): e00155.

125 Vanholder R, De Smet R, Glorieux G, Argilés A, Baurmeister $\mathrm{U}$, Brunet $\mathrm{P}$, et al. Review on uremic toxins: classification, concentration, and interindividual variability. Kidney Int. 2003;63(5):1934-43.

126 Ma YR, Xin MY, Li K, Wang H, Rao Z, Liu TX, et al. An LC-MS/MS analytical method for the determination of uremic toxins in patients with end-stage renal disease. J Pharm Biomed Anal. 2020 Aug 17;191:113551.
127 Duranton F, Cohen G, De Smet R, Rodriguez $\mathrm{M}$, Jankowski J, Vanholder $\mathrm{R}$, et al. Normal and pathologic concentrations of uremic toxins. J Am Soc Nephrol. 2012 Jul; 23(7):1258-70.

128 Grams ME, Tin A, Rebholz CM, Shafi T, Köttgen A, Perrone RD, et al. Metabolomic alterations associated with cause of CKD. Clin J Am Soc Nephrol. 2017;12(11):178794.

129 Wang K, Zelnick LR, Hoofnagle AN, Chen Y, de Boer IH, Himmelfarb J, et al. Differences in proximal tubular solute clearance across common etiologies of chronic kidney disease. Nephrol Dial Transplant. 2019 Jul 25.

130 Pawlak D, Pawlak K, Malyszko J, Mysliwiec M, Buczko W. Accumulation of toxic products degradation of kynurenine in hemodialyzed patients. Int Urol Nephrol. 2001;33(2): 399-404.

131 Rhee EP, Souza A, Farrell L, Pollak MR, Lewis GD, Steele DJ, et al. Metabolite profiling identifies markers of uremia. J Am Soc Nephrol. 2010;21:1041-51.

132 Yilmaz N, Ustundag Y, Kivrak S, Kahvecioglu S, Celik H, Kivrak I, et al. Serum indoleamine 2,3 dioxygenase and tryptophan and kynurenine ratio using the UPLC-MS/MS method, in patients undergoing peritoneal dialysis, hemodialysis, and kidney transplantation. Ren Fail. 2016 Sep;38(8):1300-9.

133 van Gelder MK, Middel IR, Vernooij RWM, Bots ML, Verhaar MC, Masereeuw R, et al. Protein-bound uremic toxins in hemodialysis patients relate to residual kidney function, are not influenced by convective transport, and do not relate to outcome. Toxins. 2020;12(4):234.

134 Sarkar SA, Wong R, Hackl SI, Moua O, Gill $\mathrm{RG}$, Wiseman A, et al. Induction of indoleamine 2,3-dioxygenase by interferon-gamma in human islets. Diabetes. 2007;56(1): 72-9.

135 Sadok I, Gamian A, Staniszewska MM. Chromatographic analysis of tryptophan metabolites. J Sep Sci. 2017;40(15):3020-45.

136 Adu-Gyamfi CG, Snyman T, Makhathini L, Otwombe K, Darboe F, Penn-Nicholson A, et al. Diagnostic accuracy of plasma kynurenine/tryptophan ratio, measured by enzyme-linked immunosorbent assay, for pulmonary tuberculosis. Int J Infect Dis. 2020; 99:441-8.

137 Seger C, Salzmann L. After another decade: LC-MS/MS became routine in clinical diagnostics. Clinical biochemistry. 2020;82:211.

138 Mor A, Kalaska B, Pawlak D. Kynurenine pathway in chronic kidney disease: what's old, what's new, and what's next? Int J Tryptophan Res. 2020;13:1178646920954882.

139 Wattanakit K, Cushman M, Stehman-Breen C, Heckbert SR, Folsom AR. Chronic kidney disease increases risk for venous thromboembolism. J Am Soc Nephrol. 2008;19(1): 135-40.
140 Drüeke TB, Massy ZA. Atherosclerosis in CKD: differences from the general population. Nat Rev Nephrol. 2010;6(12):723.

141 El-Gengaihy AE, Abdelhadi SI, Kirmani JF, Qureshi AI. 6.34 - thrombolytics. In: Taylor JB, Triggle DJ, editors. Comprehensive medicinal chemistry II. Oxford: Elsevier; 2007. p. $763-81$.

142 Shashar M, Francis J, Chitalia V. Thrombosis in the uremic milieu-emerging role of "thrombolome". Semin Dial. 2015;28(2); 198-205.

143 Potpara TS, Ferro CJ, Lip GYH. Use of oral anticoagulants in patients with atrial fibrillation and renal dysfunction. Nat Rev Nephrol. 2018;14(5):337.

144 Pawlak K, Domaniewski T, Mysliwiec M, Pawlak D. Kynurenines and oxidative status are independently associated with thrombomodulin and von Willebrand factor levels in patients with end-stage renal disease. Thromb Res. 2009 Sep;124(4):452-7.

145 Pawlak K, Myśliwiec M, Pawlak D. Kynurenine pathway - a new link between endothelial dysfunction and carotid atherosclerosis in chronic kidney disease patients. Adv Med Sci. 2010;55(2):196-203.

146 Pawlak K, Mysliwiec M, Pawlak D. Hypercoagulability is independently associated with kynurenine pathway activation in dialysed uraemic patients. Thromb Haemost. 2009 Jul;102(1):49-55.

147 Pawlak K, Tankiewicz J, Mysliwiec M, Pawlak D. Tissue factor/its pathway inhibitor system and kynurenines in chronic kidney disease patients on conservative treatment. Blood Coagul Fibrinolysis. 2009 Oct;20(7):590-4.

148 Kolachalama VB, Shashar M, Alousi F, Shivanna S, Rijal K, Belghasem ME, et al. Uremic solute-aryl hydrocarbon receptortissue factor axis associates with thrombosis after vascular injury in humans. J Am Soc Nephrol. 2018;29(3):1063-72.

149 Pawlak K, Buraczewska-Buczko A, Mysliwiec M, Pawlak D. Hyperfibrinolysis, uPA/suPAR system, kynurenines, and the prevalence of cardiovascular disease in patients with chronic renal failure on conservative treatment. Am J Med Sci. 2010 Jan;339(1):5-9.

150 Kaminski TW, Pawlak K, Karbowska M, Mysliwiec M, Grzegorzewski W, Kuna J, et al. Association between uremic toxin-anthranilic acid and fibrinolytic system activity in predialysis patients at different stages of chronic kidney disease. Int Urol Nephrol. 2018 Jan;50(1):127-35.

151 Pawlak K, Brzosko S, Mysliwiec M, Pawlak D. Kynurenine, quinolinic acid--the new factors linked to carotid atherosclerosis in patients with end-stage renal disease. Atherosclerosis. 2009 Jun;204(2):561-6.

152 Kato A, Suzuki Y, Suda T, Suzuki M, Fujie $\mathrm{M}$, Takita $\mathrm{T}$, et al. Relationship between an increased serum kynurenine/tryptophan ratio and atherosclerotic parameters in hemodialysis patients. Hemodial Int. 2010 Oct; 14(4):418-24 
153 Pawlak K, Kowalewska A, Mysliwiec M, Pawlak D. Kynurenine and its metabolites kynurenic acid and anthranilic acid are associated with soluble endothelial adhesion molecules and oxidative status in patients with chronic kidney disease. Am J Med Sci. 2009 Oct;338(4):293-300.

154 Song P, Ramprasath T, Wang H, Zou MH. Abnormal kynurenine pathway of tryptophan catabolism in cardiovascular diseases. Cell Mol Life Sci. 2017;74(16):2899-916.

155 Cole JE, Astola N, Cribbs AP, Goddard ME, Park I, Green P, et al. Indoleamine 2,3-dioxygenase- 1 is protective in atherosclerosis and its metabolites provide new opportunities for drug development. Proc Natl Acad Sci USA. 2015;112(42):13033-8.

156 Polyzos KA, Ovchinnikova O, Berg M, Baumgartner R, Agardh H, Pirault J, et al. Inhibition of indoleamine 2,3-dioxygenase promotes vascular inflammation and increases atherosclerosis in Apoe-/- mice. Cardiovasc Res. 2015;106(2):295-302.

157 Forteza MJ, Polyzos KA, Baumgartner R, Suur BE, Mussbacher M, Johansson DK, et al. Activation of the regulatory T-cell/indoleamine 2,3-dioxygenase axis reduces vascular inflammation and atherosclerosis in hyperlipidemic mice. Front Immunol. 2018; 9:950.

158 Anders HJ, Andersen K, Stecher B. The intestinal microbiota, a leaky gut, and abnormal immunity in kidney disease. Kidney Int. 2013;83(6):1010-6.

159 Koppe L, Mafra D, Fouque D. Probiotics and chronic kidney disease. Kidney Int. 2015; 88(5):958-66.

160 Meijers B, Evenepoel P, Anders HJ. Intestinal microbiome and fitness in kidney disease. Nat Rev Nephrol. 2019;15(9):531-45.

161 Vaziri ND, Wong J, Pahl M, Piceno YM, Yuan J, DeSantis TZ, et al. Chronic kidney disease alters intestinal microbial flora. Kidney Int. 2013;83(2):308-15.

162 Wong J, Piceno YM, DeSantis TZ, Pahl M, Andersen GL, Vaziri ND. Expansion of urease- and uricase-containing, indole- and pcresol-forming and contraction of shortchain fatty acid-producing intestinal microbiota in ESRD. Am J Nephrol. 2014;39(3): 230-7.

163 Sampaio-Maia B, Simões-Silva L, Pestana M, Araujo R, Soares-Silva IJ. The role of the gut microbiome on chronic kidney disease. Adv Appl Microbiol. 2016;96:65-94.

164 Jiang S, Xie S, Lv D, Wang P, He H, Zhang $\mathrm{T}$, et al. Alteration of the gut microbiota in Chinese population with chronic kidney disease. Sci Rep. 2017;7(1):2870-0.

165 Sabatino A, Regolisti G, Brusasco I, Cabassi A, Morabito S, Fiaccadori E. Alterations of intestinal barrier and microbiota in chronic kidney disease. Nephrol Dial Transplant. 2014;30(6):924-33.

166 Lau WL, Kalantar-Zadeh K, Vaziri ND. The gut as a source of inflammation in chronic kidney disease. Nephron. 2015;130(2):92-8.
167 Chelakkot C, Ghim J, Ryu SH. Mechanisms regulating intestinal barrier integrity and its pathological implications. Exp Mol Med. 2018;50(8):103-9.

168 Lee B, Moon KM, Kim CY. Tight junction in the intestinal epithelium: its association with diseases and regulation by phytochemicals. J Immunol Res. 2018;2018:2645465-5.

169 Kim HY, Yoo TH, Hwang Y, Lee GH, Kim $\mathrm{B}$, Jang J, et al. Indoxyl sulfate (IS)-mediated immune dysfunction provokes endothelial damage in patients with end-stage renal disease (ESRD). Sci Rep. 2017;7(1):3057.

170 Ranganathan N, Friedman EA, Tam P, Rao V, Ranganathan P, Dheer R. Probiotic dietary supplementation in patients with stage 3 and 4 chronic kidney disease: a 6-month pilot scale trial in Canada. Curr Med Res Opin. 2009 Aug;25(8):1919-30.

171 Ranganathan N, Ranganathan P, Friedman EA, Joseph A, Delano B, Goldfarb DS, et al. Pilot study of probiotic dietary supplementation for promoting healthy kidney function in patients with chronic kidney disease. Adv Ther. 2010 Sep;27(9):634-47.

172 Miranda Alatriste PV, Urbina Arronte R, Gómez Espinosa CO, Espinosa Cuevas ML. Effect of probiotics on human blood urea levels in patients with chronic renal failure. Nutr Hosp. 2014 Mar 1;29(3):582-90.

173 Wang IK, Wu YY, Yang YF, Ting IW, Lin $\mathrm{CC}, \mathrm{Yen} \mathrm{TH}$, et al. The effect of probiotics on serum levels of cytokine and endotoxin in peritoneal dialysis patients: a randomised, double-blind, placebo-controlled trial. Benef Microbes. 2015;6(4):423-30.

174 Fagundes RAB, Soder TF, Grokoski KC, Benetti F, Mendes RH. Probiotics in the treatment of chronic kidney disease: a systematic review. J Bras Nefrol. 2018 Jul-Sep; 40(3):278-86.

175 Clarke G, Grenham S, Scully P, Fitzgerald P, Moloney RD, Shanahan F, et al. The microbiome-gut-brain axis during early life regulates the hippocampal serotonergic system in a sex-dependent manner. Mol Psychiatry. 2013;18(6):666-73.

176 El Aidy S, Kunze W, Bienenstock J, Kleerebezem $\mathrm{M}$. The microbiota and the gut-brain axis: insights from the temporal and spatial mucosal alterations during colonisation of the germfree mouse intestine. Benef Microbes. 2012;3(4):251-9.

177 Kwon HK, Lee CG, So JS, Chae CS, Hwang JS, Sahoo A, et al. Generation of regulatory dendritic cells and CD4+Foxp3+ T cells by probiotics administration suppresses immune disorders. Proc Natl Acad Sci USA. 2010;107(5):2159-64.

178 Atarashi K, Tanoue T, Shima T, Imaoka A, Kuwahara T, Momose Y, et al. Induction of colonic regulatory $\mathrm{T}$ cells by indigenous Clostridium species. Science. 2011 Jan 21; 331(6015):337-41.

179 Dolpady J, Sorini C, Di Pietro C, Cosorich I, Ferrarese R, Saita D, et al. Oral probiotic VSL\#3 prevents autoimmune diabetes by modulating microbiota and promoting indoleamine 2,3-dioxygenase-enriched tolerogenic intestinal environment. J Diabetes Res. 2016;2016:7569431.

180 Esmaeili SA, Mahmoudi M, Rezaieyazdi Z, Sahebari M, Tabasi N, Sahebkar A, et al Generation of tolerogenic dendritic cells using Lactobacillus rhamnosus and Lactobacillus delbrueckii as tolerogenic probiotics. J Cell Biochem. 2018;119(9):7865-72.

181 Zhao L, Suolang Y, Zhou D, Tang Y, Zhang Y. Bifidobacteria alleviate experimentally induced colitis by upregulating indoleamine 2 , 3 -dioxygenase expression. Microbiol Immunol. 2018;62(2):71-9.

182 Kalinina O, Talley S, Zamora-Pineda J, Paik W, Campbell EM, Knight KL. Amelioration of graft-versus-host disease by exopolysaccharide from a commensal bacterium. J Immunol. 2021 May 1;206(9):2101-8.

183 Valladares R, Bojilova L, Potts AH, Cameron E, Gardner C, Lorca G, et al. Lactobacillus johnsonii inhibits indoleamine 2,3-dioxygenase and alters tryptophan metabolite levels in BioBreeding rats. Faseb J. 2013 Apr; 27(4):1711-20.

184 Lima WC, Varani AM, Menck CF. NAD biosynthesis evolution in bacteria: lateral gene transfer of kynurenine pathway in Xanthomonadales and Flavobacteriales. Mol Biol Evol. 2009 Feb;26(2):399-406.

185 Ternes CM, Schönknecht G. Gene transfers shaped the evolution of de novo NAD+ biosynthesis in eukaryotes. Genome Biol Evol. 2014 Sep;6(9):2335-49.

186 Yuasa HJ, Ushigoe A, Ball HJ. Molecular evolution of bacterial indoleamine 2,3-dioxygenase. Gene. 2011 Oct 1;485(1):22-31.

187 Zheng D, Liwinski T, Elinav E. Interaction between microbiota and immunity in health and disease. Cell Res. 2020;30(6):492-506.

188 Forsythe P, Inman MD, Bienenstock J. Oral treatment with live Lactobacillus reuteri inhibits the allergic airway response in mice. Am J Respir Crit Care Med. 2007;175(6): 561-9.

189 Acovic A, Gazdic M, Jovicic N, Harrell CR Fellabaum C, Arsenijevic N, et al. Role of indoleamine 2,3-dioxygenase in pathology of the gastrointestinal tract. Therap Adv Gastroenterol. 2018;11:1756284818815334.

190 Qi H, Li Y, Yun H, Zhang T, Huang Y, Zhou $\mathrm{J}$, et al. Lactobacillus maintains healthy gut mucosa by producing L-Ornithine. Commun Biol. 2019;2(1):171.

191 Lanis JM, Alexeev EE, Curtis VF, Kitzenberg DA, Kao DJ, Battista KD, et al. Tryptophan metabolite activation of the aryl hydrocarbon receptor regulates IL-10 receptor expression on intestinal epithelia. Mucosal Immunol. 2017;10(5):1133-44.

192 Shin JH, Lee YK, Shon WJ, Kim B, Jeon CO, Cho JY, et al. Gut microorganisms and their metabolites modulate the severity of acute colitis in a tryptophan metabolism-dependent manner. Eur J Nutr. 2020;59(8):3591601 . 
193 Zelante T, Iannitti RG, Cunha C, De Luca A, Giovannini G, Pieraccini G, et al. Tryptophan catabolites from microbiota engage aryl hydrocarbon receptor and balance $\mathrm{mu}$ cosal reactivity via interleukin-22. Immunity. 2013;39(2):372-85.

194 Laurans L, Venteclef N, Haddad Y, Chajadine M, Alzaid F, Metghalchi S, et al. Genetic deficiency of indoleamine 2,3-dioxygenase promotes gut microbiota-mediated metabolic health. Nat Med. 2018;24(8): 1113-20.
195 Evenepoel P, Meijers BK, Bammens BR, Verbeke K. Uremic toxins originating from colonic microbial metabolism. Kidney Int Suppl. 2009;76:S12-9.

196 Vanholder R, Schepers E, Pletinck A, Nagler $\mathrm{EV}$, Glorieux G. The Uremic toxicity of indoxyl sulfate and p-cresyl sulfate: a systematic review. J Am Soc Nephrol. 2014;25(9): 1897-907.

197 Chiara B, Giorgio G, Marco C, Manrico B, Claudio B, Pietro A. Indoxyl sulfate: a candidate target for the prevention and treatment of cardiovascular disease in chronic kidney disease. Current Drug Targets. 2015; 16(4):366-72.
198 Hung SC, Kuo KL, Wu CC, Tarng DC. Indoxyl sulfate: a novel cardiovascular risk factor in chronic kidney disease. J Am Heart Assoc. 2017;6(2):e005022.

199 Yamaguchi J, Tanaka T, Inagi R. Effect of AST-120 in chronic kidney disease treatment: still a controversy? Nephron. 2017; 135(3):201-6.

200 Finger EB, Bluestone JA. When ligand becomes receptor: tolerance via $\mathrm{B} 7$ signaling on DCs. Nat Immunol. 2002;3(11):1056-7. 